\title{
- Final Report - Magma Energy Research Project
}

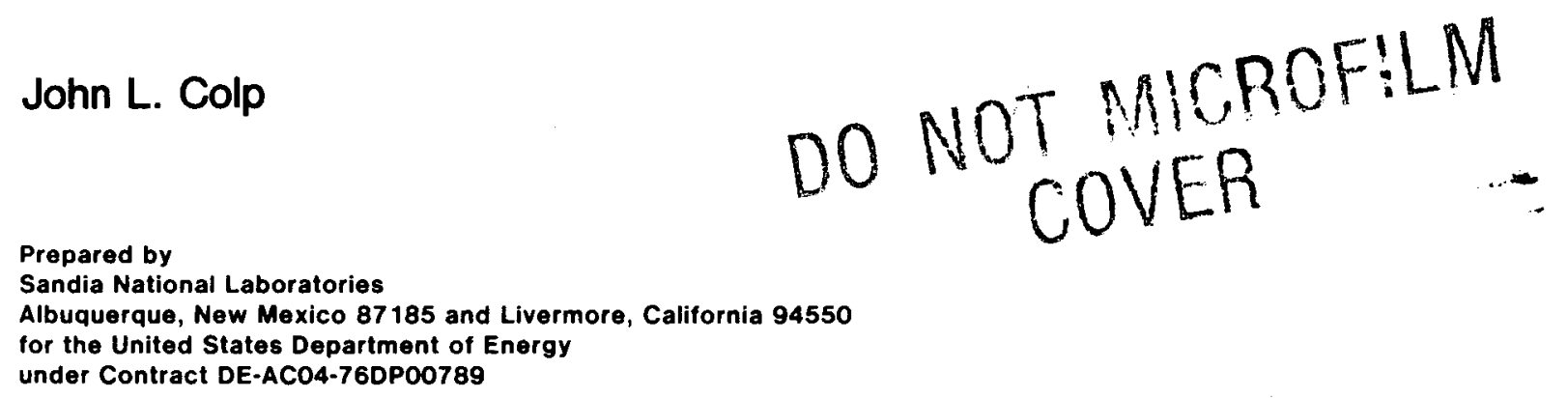




\section{DISCLAIMER}

Portions of this document may be illegible in electronic image products. Images are produced from the best available original document. 
Issued by Sandia National Laboratories, operated for the United States Department of Energy by Sandia Corporation.

NOTICE: This report was prepared as an account of work sponsored by an agency of the United States Government. Neither the United States Government nor any agency thereof, nor any of their employees, nor any of their contractors, subcontractors, or their employees, makes any warranty, express or implied, or assumes any legal liability or responsibility for the accuracy, completeness, or usefulness of any information, apparatus, product, or process disclosed, or represents that its use would not infringe privately owned rights. Reference herein to any specific commercial product, process, or service by trade name, trademark, manufacturer, or otherwise, does not necessarily constitute or imply its endorsement, recommendation, or favoring by the United States Government, any agency thereof or any of their y the contractors or subcontractors. The views and opinions expressed herein do not necessarily state or reflect those of the United States Government, any agency thereof or any of their contractors or subcontractors.

Printed in the United States of America Available from

Available from .

National Technical Information Service

U.S. Department of Commerce

5285 Port Royel Road

Springfield, VA 22161

NTIS price codes

Printed copy: A03

Microfiche copy: A01

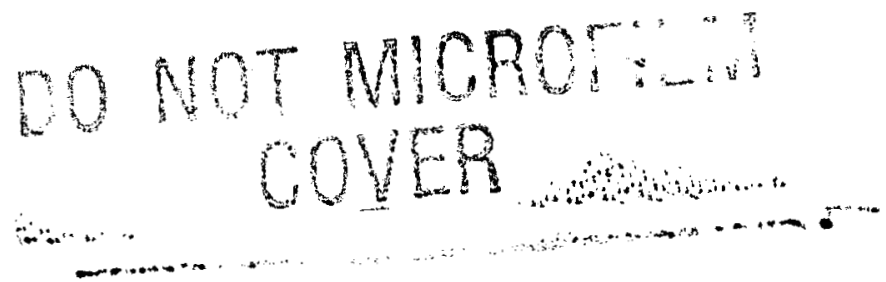


SAND82-2377

Unlimited Release

Printed October 1982
Distribution

Category UC-66

\title{
Final Report - \\ Magma Energy Research Project
}

\author{
John L. Colp \\ Geophysics Division 1541 \\ Sandia National Laboratories \\ Albuquerque, NM 87185
}

\begin{abstract}
The DOE-funded, 7-yr research project conducted by Sandia National Laboratories to assess the scientific feasibility of extracting energy directly from buried magma sources in the upper $10 \mathrm{~km}$ of the earth's crust has been completed successfully. Scientific feasibility (the demonstration, by means of theoretical calculations and supporting laboratory and field measurements, that there are no known insurmountable theoretical or physical barriers which invalidate a concept or process) was demonstrated for the concept of magma energy extraction. The US magma resource is estimated at 50000 to 500000 quads of energy - a 700- to 7000-yr supply at the current US total energy use rate of 75 quads per year. Existing geophysical exploration systems are believed capable of locating and defining magma bodies and were demonstrated over a known shallow buried molten-rock body. Drilling rigs that can drill to the depths required to tap magma are currently available and experimental boreholes were drilled well into buried molten rock at temperatures up to $1100^{\circ} \mathrm{C}$. Engineering materials compatible with the buried magma environment are available and their performances were demonstrated in analog laboratory experiments. Studies show that energy can be extracted at attractive rates from magma resources in all petrologic compositions and physical configurations. Downhole heat extraction equipment was designed, built, and demonstrated successfully in buried molten rock and in the very hot margins surrounding it. Two methods of generating gaseous fuels in the hightemperature magmatic environment - generation of $\mathrm{H}_{2}$ by the interaction of water with the ferrous iron and $\mathrm{H}_{2}, \mathrm{CH}_{4}$, and $\mathrm{CO}$ generation by the conversion of waterbiomass mixtures - have been investigated and show promise.
\end{abstract}




\section{Acknowledgments}

Over the 7-yr this project has been underway, many people, within and outside of Sandia National Laboratories, have contributed greatly to its overall success. Their efforts and encouragement are especially appreciated by the author.

The contributions of Terrence M. Gerlach on his volcanic gas studies, William C. Luth on his magma petrology studies, and Harry C. Hardee and James C. Dunn on their energy extraction studies are acknowledged with thanks. The author thanks Harry C. Hardee, William C. Luth, and Richard K. Traeger for their many valuable comments on the overall report. 


\section{Contents}

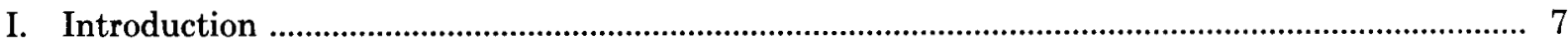

Objective of the Project .................................................................................................................. 7

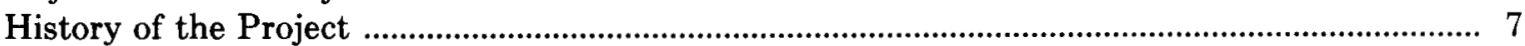

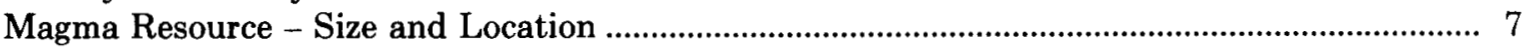

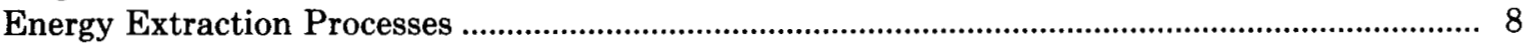

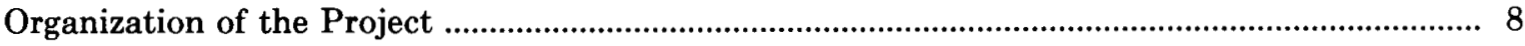

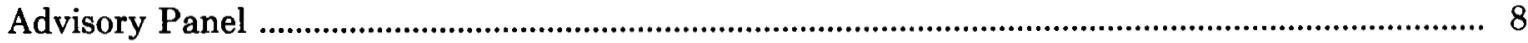

Workshop and Symposia Participation …................................................................................... 9

Other Scientific Program Impacts ................................................................................................ 9

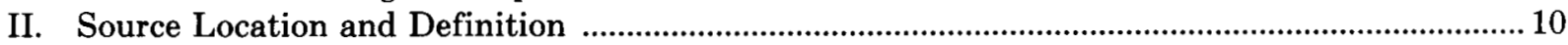

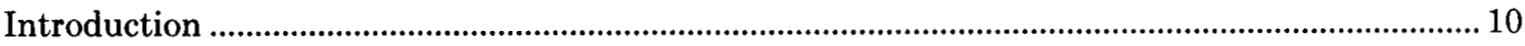

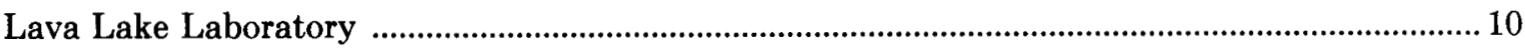

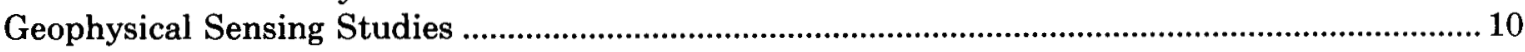

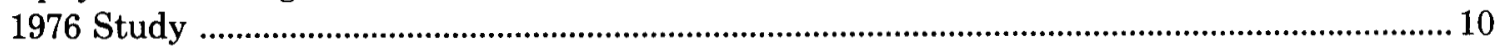

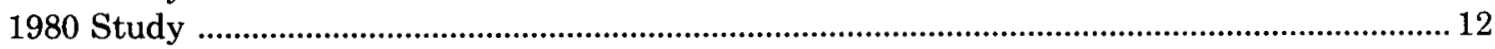

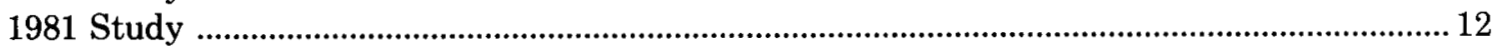

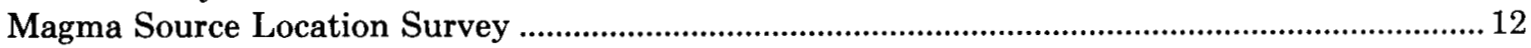

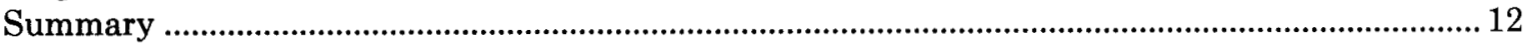

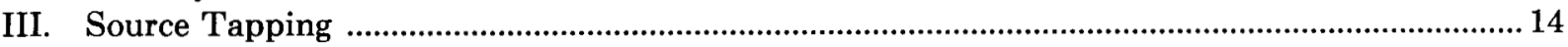

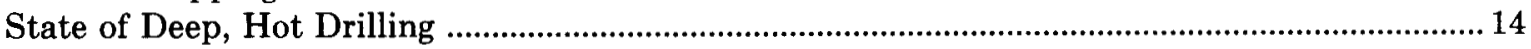

Rock Drillability and Borehole Stability Studies ............................................................................... 14

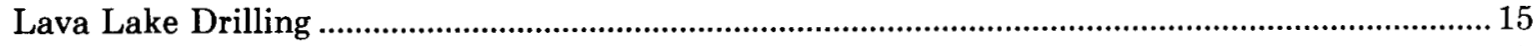

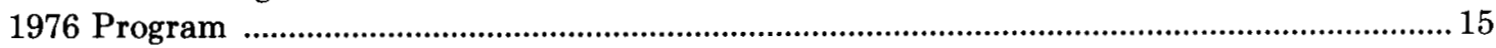

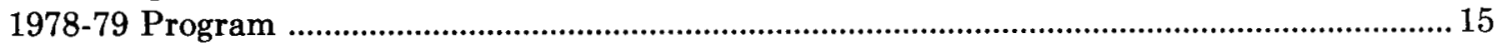

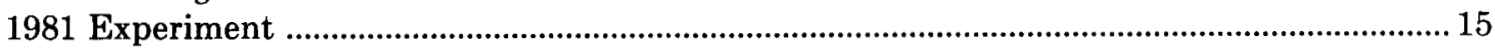

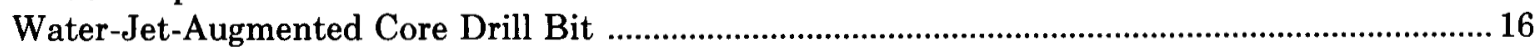

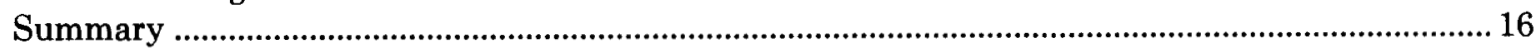

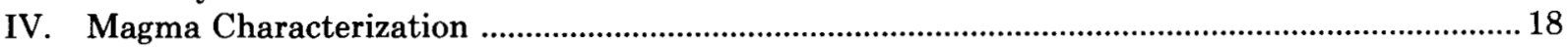

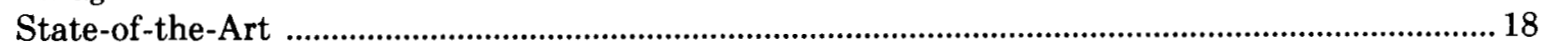

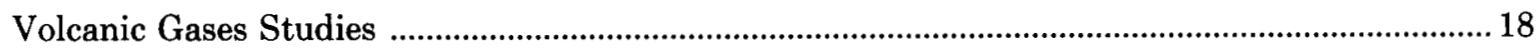

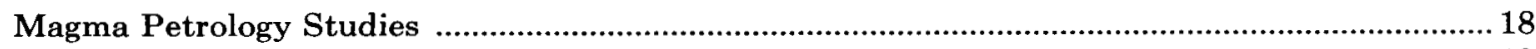

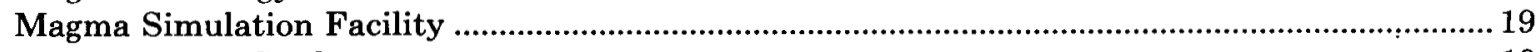

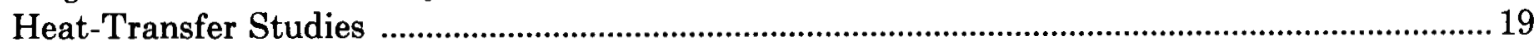

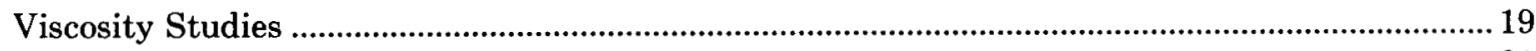

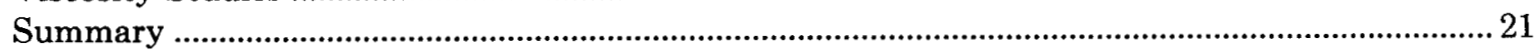

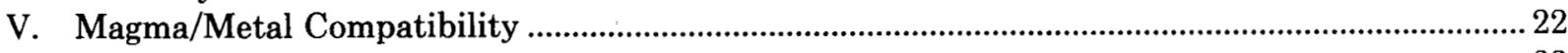

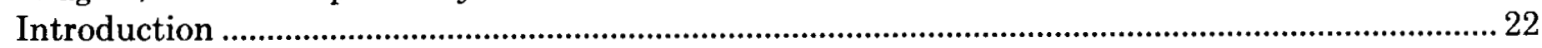

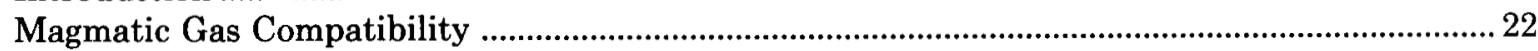

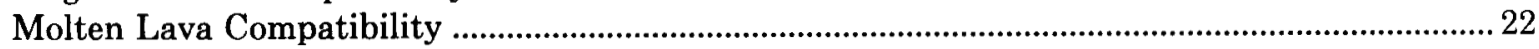

Pure Metal Compatibility Tests .................................................................................................... 22

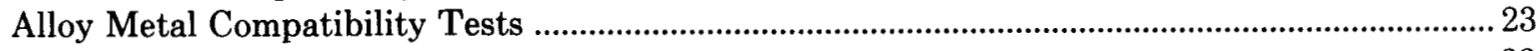

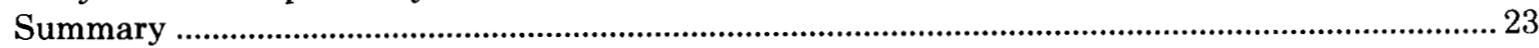




\section{Contents (cont)}

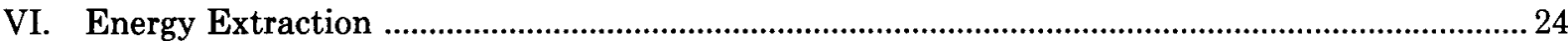

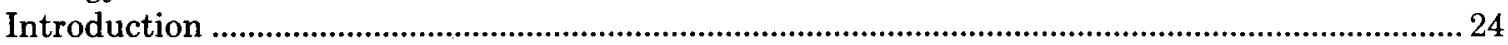

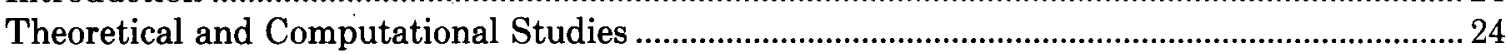

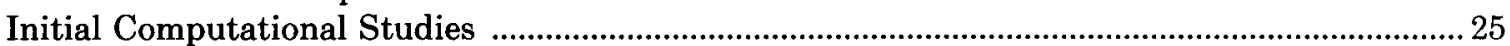

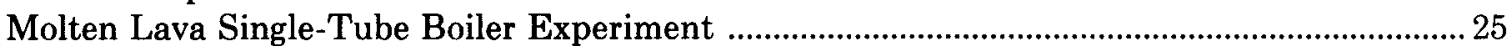

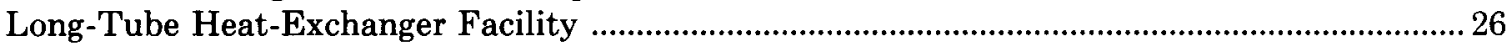

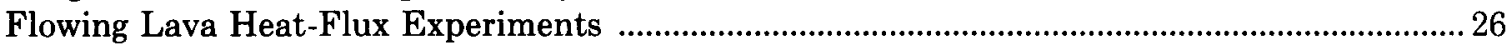

Molten Lava Heat-Flux Laboratory Experiments ......................................................................... 27

Lava Lake Extraction Experiments ............................................................................................. 27

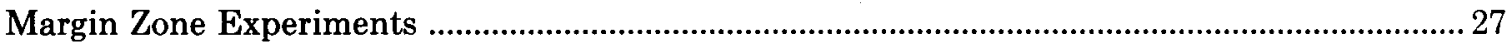

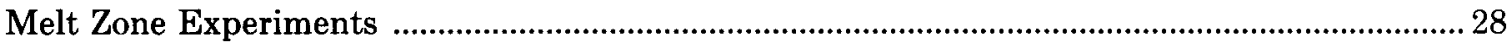

Magma In Situ Convection Laboratory Experiments ................................................................... 30

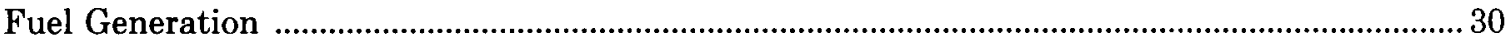

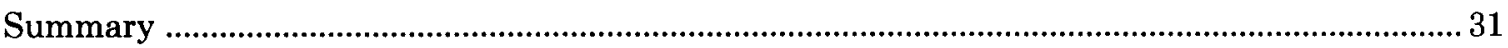

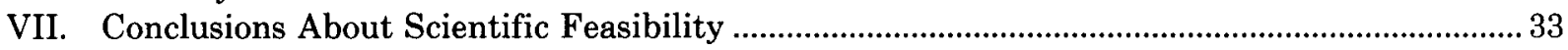

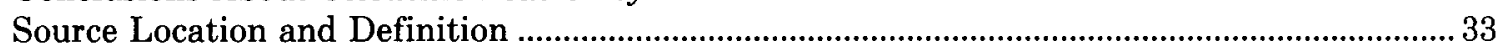

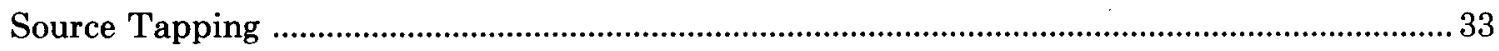

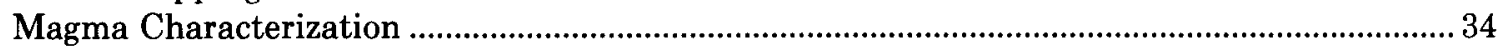

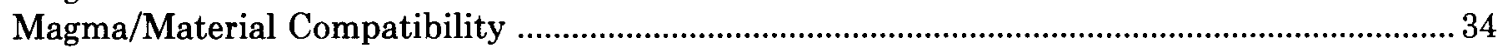

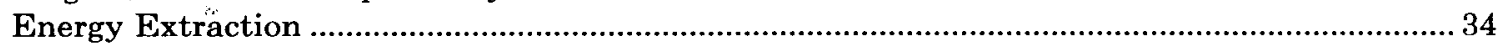

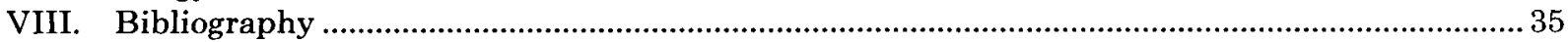

\section{Figures}

1. 1976 Kilauea Iki Geophysical Sensing Experiments, Results Showing Lateral Boundary

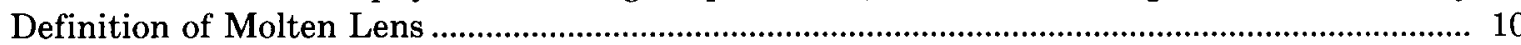

2. Proposed Model of Vertical Section Through Kilauea Iki Lava Lake ..................................... 11

3. Comparison of Lava Lake Molten Lens Lateral Boundary Measurements in 1976 and 1980 .. 12

4. Temperature and Seismic Velocity vs Depth in Kilauea Iki Lava Lake ................................. 12

5. Stress-Strain Curve of Dry Mt. Hood Andesite With Confining Pressure $=100 \mathrm{MPa}$ Showing

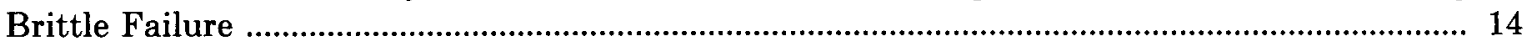

6. Water-Jet-Augmented Core Drill Bit Showing Face-Discharge Coolant Nozzles ...................... 16

7. Model of Kilauea Iki Lava Lake Vertical Structure Based on 1981 Core Sample Study ......... 18

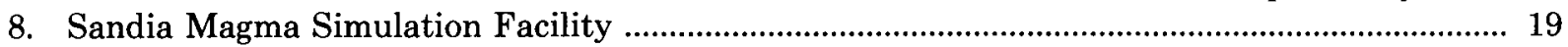

9. Magma in situ Convection Results Using Cuberio Basalt at 2 kbar Pressure ........................... 19

10. Viscosity Data Summary - Various Basalts (1 bar) ...................................................................... 20

11. Viscosity Data Summary - With Reduced Bubble Formation ............................................. 20

12. Schematic of the Molten Lava/Single-Tube Boiler Experiment ............................................. 25

13. Single-Tube Boiler as Removed From Molten Lava Showing Solidified Lava Crust Encasing Stainless Steel Boiler Tube .............................................................................................................. 26

14. Convection Heat Flux Data From Laboratory Measurements in Basalt ................................ 27

15. Schematic Drawing of 1981 Lava Lake Open Heat-Exchanger Experiment .............................. 28

16. 1981 Lava Lake Open Heat-Exchanger Experiment Results Showing Heat-Flux Measurements Based on Original Borehole Area ............................................................................................... 29

17. 1981 Lava Lake Open Heat-Exchanger Experiment Results Showing the Growth in Energy Exchange Area with Time

\section{Tables}

1. Magma Energy Research Advisory Panel ....................................................................................... 8

2. 1976 Kilauea Iki Geophysical Sounding Experiments With Preliminary Results ….................. 11

3. Magma/Metal Environments .................................................................................................... 22 


\section{Final Report - Magma Energy Research Project}

\section{Introduction}

\section{Objective of the Project}

The objective of the Magma Energy Research Project from its FY 75 inception has been to assess the scientific feasibility of extracting energy directly from deeply buried magma sources. We defined "scientific feasibility" as the demonstration, by means of theoretical calculations and supporting laboratory and field measurements, that there are no known insurmountable theoretical or physical barriers that invalidate a concept or process. We recognize that scientific feasibility can be defined at a series of levels. We settled on the definition stated after much discussion and with the concurrence of the members of the Magma Energy Research Advisory Panel. The assessment was concentrated in the areas of source location, magma properties, material compatibility, energy extraction, and source tapping, with the source tapping aspect centering on the rock mechanics of a hole drilled into the temperature/pressure regime associated with deep magma. Although no extensive investigation on molten-rock drilling was considered, as the project continued some drilling development became necessary to support the other parts of the project.

\section{History of the Project}

During the summer of 1973, Sandia Laboratories initially proposed to the AEC a study on the potential of magma energy as an alternative energy resource. Active investigations, begun during the Fall of that year, were at first simply informal discussions among various volcanologists and geothermal specialists from around the country. For the most part, people were rather skeptical about the proposal. However, to more objectively assess the problems, simple laboratory experiments on the high-temperature properties of tholeiite basalt at atmospheric pressure, the effect of molten rock on some common metals, and thermal calculations suggested that use of magma energy was potentially viable and scientific interest increased.
In February of 1974, we participated in the Utilization of Volcano Energy Conference at Hilo, Hawaii, cosponsored by the Japanese and by the US National Science Foundation. The proceedings were published by Sandia (Colp and Furumoto, 1974). The impact of this conference was to attract international attention to the concept of magma energy use and to provide the project with an increased level of scientific interest.

ERDA's Division of Physical Research funded the Magma Energy Research Project for FY 75. Existing efforts at Sandia on planning, laboratory investigations, and calculational studies continued. Our interactions with universities and the US Geological Survey increased. A formal panel of experts in related fields was selected to advise the laboratory on this work. A milestone event during the initial year of funding was a Magma Workshop in March 1975 with 30 American and Japanese scientists participating (Colp et al, 1975). Recommendations from this workshop were used extensively to plan and direct our later efforts on assessing the scientific feasibility of locating and defining magma, and characterizing its chemical and physical properties.

Funding for the project continued without a break from FY 75 until the scientific feasibility of this concept was demonstrated in FY 82. Total funding for the project was $\$ 4.9 \mathrm{M}$ with approximately $\$ 1 \mathrm{M}$ going to universities and other research groups. This research showed that the extraction of energy from magma bodies was scientifically feasible. This report will describe in some detail the results accomplished in that period.

\section{Magma Resource - Size and Location}

Estimates of the size of the magma resource in the United States have come from the work of Smith and Shaw $(1975,1979)$ of the United States Geological Survey. They estimate that the total igneous-related 
resource within the top $10 \mathrm{~km}$ of the crust is $10^{23}$ to $10^{24} \mathrm{~J}\left(10^{5}\right.$ to $10^{6}$ quads), with about half in a molten or partially molten state. Their estimate of 50000 to 500 000 quads of magma is equivalent to a $700-$ to $7000-\mathrm{yr}$ US energy supply at the current annual total energy consumption rate of 75 quads. Approximately $90 \%$ of this estimated resource is located in the western counterminous United States. Most of it is believed to exist as silicic volcanic systems with initial temperatures on the order of $850^{\circ} \mathrm{C}$ or greater.

A much larger magma resource is believed to exist at the spreading margins of the tectonic plates of the world. Although no evaluation of this resource similar to the Smith and Shaw work has been made, its magnitude can be roughly estimated. A model of an inner rift valley has been proposed by Moore et al (1974) in which they estimate the molten portion to be 1 to $15 \mathrm{~km}$ wide by $6 \mathrm{~km}$ high. The plate-spreading margins of the world are estimated to have a length on the order of $60000 \mathrm{~km}$. A rough estimate of the chamber volume worldwide would therefore be from 3 to 15 times the volume of the United States' magma resource. Although this resource is located generally $2.5 \mathrm{~km}$ below the surface of the world's oceans, it has the advantages of being basic volcanic systems with initial temperatures on the order of $1000^{\circ}$ to $1200^{\circ} \mathrm{C}$ and of being only a kilometer or so below the ocean floor.

\section{Energy Extraction Processes}

Three energy extraction processes were examined for their scientific feasibility. The first and simplest is to insert a heat exchanger (either closed or open) directly into the magma or its very hot margins, pump down a heat-transfer fluid (water), extract the resulting steam, and feed it through a conventional turbine/ generator to produce electrical power. The second process is to use the interaction of water with ferrousiron-oxide in magma or very hot rock to generate hydrogen $\left(\mathrm{H}_{2}\right)$. The third process is the conversion of water-biomass mixtures at the high temperatures in the magmatic environment to generate hydrogen, methane, and carbon monoxide. The latter two processes result in the production of transportable products that can be used as fuels or chemical feedstocks, both of which are forms of energy expected to be in critically short supply in the future.

We have demonstrated that all three energy extraction processes examined are scientifically feasible.

\section{Organization of the Project}

We organized this project into five technologically independent task areas that could be studied for assessing scientific feasibility. These tasks were:

- Source Location and Definition

- Source Tapping

- Magma Characterization

- Magma/Material Compatibility

- Energy Extraction

The task organization is followed in describing the results in the balance of this report.

\section{Advisory Panel}

At the outset of the formal Magma Energy Research Project (late 1974), we recognized the necessity of having a group of highly qualified, active researchers from the various engineering and geoscience fields related to our investigations to provide technical advice on our plans and progress. Accordingly, the Magma Energy Research Advisory Panel was established; careful coverage of all the disciplines required using USGS and university researchers (see Table 1). Although the participants on this panel varied over the span of the investigation, continuity was carefully maintained by retaining several members for the duration of its existence. Panel meetings were held whenever deemed advisable, a practice that resulted in about two meetings per year. Each principal investigator reported his progress and the panel discussed what had been done and made suggestions for future directions of research. This format worked very well and the contributions of the various panel members were valuable to the progress of the project.

\begin{tabular}{|c|c|c|}
\hline $\begin{array}{l}\text { Prof. William Brigham } \\
\text { Stanford University }\end{array}$ & Energy Extraction & 1974-1976 \\
\hline $\begin{array}{l}\text { Dr. Robert Decker } \\
\text { Dartmouth College \& } \\
\text { US Geol. Survey }\end{array}$ & Volcanology/Geophysics & $1974-1981$ \\
\hline $\begin{array}{l}\text { Dean Gordon Eaton } \\
\text { US Geol. Survey/ } \\
\text { Texas A\&M University }\end{array}$ & Volcanology/Geophysics & $1977-1981$ \\
\hline $\begin{array}{l}\text { Prof. Melvin Friedman } \\
\text { Texas A\&M University }\end{array}$ & $\begin{array}{l}\text { Tectonophysics/Rock } \\
\text { Deformation }\end{array}$ & $1974-1981$ \\
\hline $\begin{array}{l}\text { Prof. John F. Hermance } \\
\text { Brown University }\end{array}$ & Geophysics/Electrical & $1974-1981$ \\
\hline $\begin{array}{l}\text { Dr. James G. Moore } \\
\text { US Geological Survey }\end{array}$ & Magma Petrology & $1976-1981$ \\
\hline $\begin{array}{l}\text { Dr. Dallas Peck } \\
\text { US Geological Survey }\end{array}$ & Magma Petrology & $1974-1976$ \\
\hline $\begin{array}{l}\text { Dean Roger Staehle } \\
\text { Ohio State Univ./ } \\
\text { Univ. of Minnesota }\end{array}$ & Material Corrosion & $1974-1981$ \\
\hline $\begin{array}{l}\text { Dr. Peter Ward } \\
\text { US Geological Survey }\end{array}$ & Geophysics/Seismic & $1974-1981$ \\
\hline
\end{tabular}

\section{Table 1. Magma Energy Research}

Prof. William Brigham Stanford University

Dr. Robert Decker

Dartmouth College \&

US Geol. Survey

Dean Gordon Eaton

Texas A\&M University

Prof. Melvin Friedman

Texas A\&M University

Tectonophysics/Rock

$1974-1981$

Brown University

Dr. James G. Moore

US Geological Survey

Dr. Dallas Peck

US Geological Survey

Dean Roger Staehle

Dr. Peter Ward

US Geological Survey

Energy Extraction

Volcanology/Geophysics

Volcanology/Geophysics 


\section{Workshop and Symposia Participation}

The scientific results achieved during the progress of the project have received national and international recognition and participants have been invited to participate in various workshops and symposia. These are tabulated below:

Sandia/USGS Magma Workshop

IAVCEI Intraplate Volcanism Symposium

UNITAR Long-Term Energy Resources Conference 1979

IAVCEI Arc Volcanism Symposium

\section{Other Scientific Program Impacts}

A number of other related scientific programs have been impacted and/or funded during the operation of the Magma Energy Research Project. These include various universities and other government agencies:
Arizona State University

Brown University

Massachusetts Institute

of Technology

Texas A\&M University

University of Alaska

University of Texas, Austi

University of Texas, Dallas

US Geological Survey

US Geological Survey

US Geological Survey
Magma Geochemistry

Electromagnetic Sensing

Seismic Sensing

$1978-80$

Rock

Rock Mechanics/Borehole Stability

Volcano Seismic Study 1975

Electromagnetic Sensing

Seismic Sensing

Lava Lake Studies

Geophysical Sensing

Volcano Eruption Support

1981

1980
1976-1981

1976,1978

1980,1981 


\section{Source Location and Definition}

\section{Introduction}

A significant question is, Do magma sources presently exist in the upper $10 \mathrm{~km}$ of the earth's crust? The answer, There is evidence-actual and inferredthat sources do exist now. Most earth scientists believe that molten and partially molten sources do exist within this depth range. Smith and Shaw (1975) list 47 silicic volcano centers less than $10 \mathrm{~km}$ deep in the US where there is enough evidence for them to estimate the thermal energy contained in the molten or partially molten state. The evidence they use to select these centers include surface expressions (calderas, dated lava flows, fracture patterns, and uplift) and geophysical anamolies (gravity, magnetics, seismic, and others).

\section{Lava Lake Laboratory}

The Magma Energy Research Project was fortunate to have available a mass of molten rock within easily drillable depths for use as a field laboratory. This site was the Kilauea Iki crater, a prehistoric pit crater in the Hawaii Volcanoes National Park that was half-filled with molten lava to a depth of about $400 \mathrm{ft}$ during an eruption in November-December 1959. Although not a true magma deposit, the only significant differences between this ponded lava flow and that of a magma body is size, gas content, and depth. Temperatures and other material properties are close enough to real magma to provide a realistic laboratory. This fortuitous gift of nature was used as fully as allowed in our research on magma energy.

\section{Geophysical Sensing Studies}

We sponsored and conducted three series of geophysical sensing studies over the molten lens of Kilauea Iki lava lake. The purpose of these studies was to demonstrate the capability and accuracy of a variety of geophysical sensing techniques to correctly identify and define the areal extent (lateral boundary), depth, and thickness of the molten lens and to measure in situ properties of the melt. This site was chosen with the consensus of the Magma Workshop because it was the only accessible location where a molten rock body was known (from previous USGS drilling results) to exist. At the time we selected it, nothing was known about the areal extent or thickness of the molten lens, although some dimensions were inferred from calculated cooling models.

\section{Study}

The purpose of the first Sandia lava lake sensing experiment was to define the lateral boundary, depth, and thickness of the melt. The principal investigators and results of the boundary definition experiments are shown in Figure 1; results of the depth and thickness experiments are shown in Table 2. Hermance et al (1979) and Hermance and Colp (1982) provide detailed descriptions of these experiments and summaries of their interpretations.

Following the completion of the first lava lake sensing study, we arranged for Dr. John Hermance, Brown University, to gather the results from the experimenters and prepare a vertical model of the lava lake (Hermance et al, 1979). This model is shown in Figure 2.

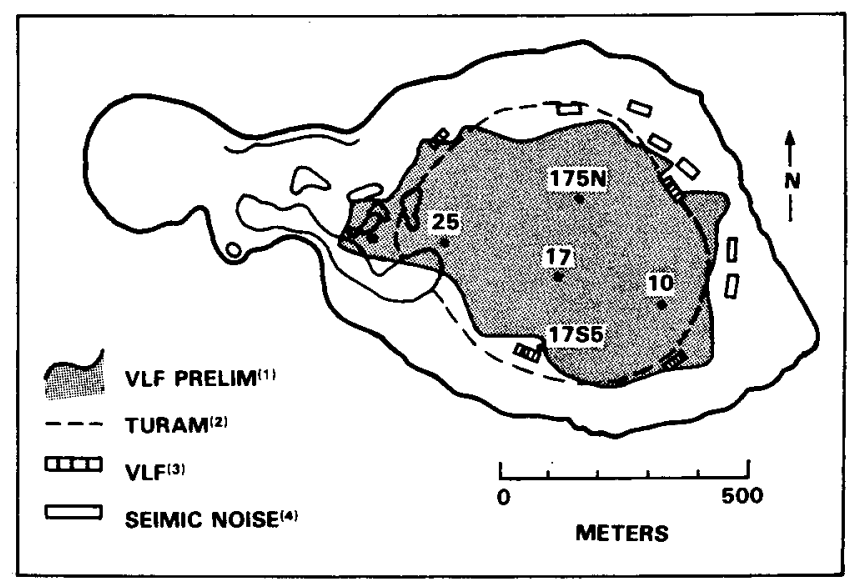

NOTE: $\quad 1$. Anderson, 1976

2. and 3. Flanigan and Zablocki, 1977

4. Colp and Traeger, 1980.

Figure 1. 1976 Kilauea Iki Geophysical Sensing Experiment, Results Showing Lateral Boundary Definition of Molten Lens. 
Table 2. 1976 Kilauea Iki Geophysical Sounding Experiments With Preliminary Results

\begin{tabular}{llcrl}
$\begin{array}{l}\text { Principal } \\
\text { Inveatigator }\end{array}$ & \multicolumn{1}{c}{$\begin{array}{c}\text { Sensing Technique } \\
\text { Used }\end{array}$} & $\begin{array}{c}\text { Depth to Melt Thickness } \\
(\mathbf{m})\end{array}$ & $\begin{array}{c}\text { Melt } \\
\text { (m) }\end{array}$ & References \\
\hline & & & & \\
Aki (MIT) & Active and Passive Seismic & $\sim 45$ & $<10$ & Aki et al, 1978 \\
USGS & Schlumberger Sounding & $44(?)$ & - & Zablocki, 1976 \\
USGS & E-M (two-loop) Sounding & 45 & $17-18$ & Smith et al, 1977 \\
& & 45 & $35-45$ & Smith et al, 1978 \\
Bostick (UTA) Audiomagnetotelluric & $(45,7)$ & 4.6 & Bostick et al, 1977 \\
\hline
\end{tabular}

The completion of this initial study brought several facts to our attention:

- The geophysical sensing techniques used can provide the desired measurements but the in situ properties, especially the electrical conductivity and seismic velocity, of the melt and enclosing crust must be measured to implement the correct interpretation of the measured values.

- No single geophysical system is adequate to provide an unambiguous measurement of the desired quantities. A successful exploration program must use all possible sensing systems and interrelate their individual results in an overall interpretation.

- The lava lake site selected was geophysically quite complex because of the extensive fracturing of the overlying crust with its contained hydrothermal system. However, it is highly probable that a real magma exploration site will be equally or even more complex.

- A drilling program to determine the actual dimensions of the lava lake molten lens must be started.

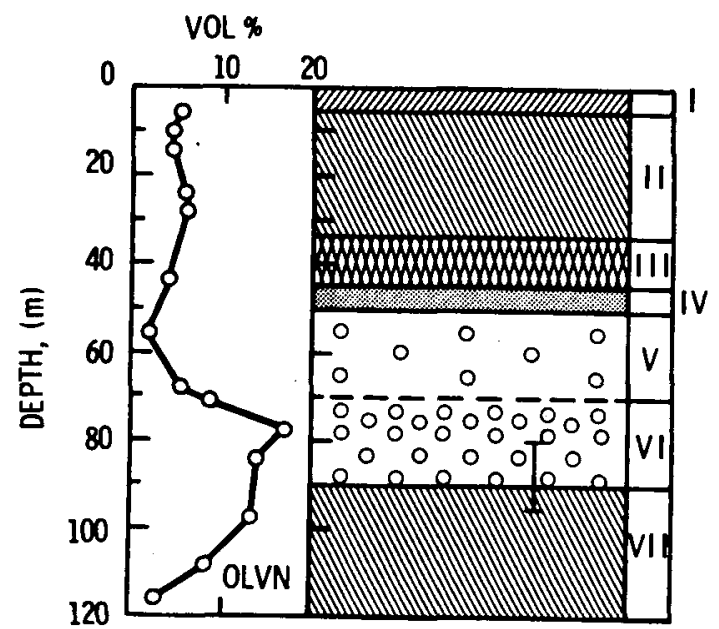

Layer I A dry, resistive surface layer from the surface to approximately $5 \mathrm{~m}$.

Layer II A warm, wet layer at $100^{\circ} \mathrm{C}$, containing appreciable water and/or steam from 5 $\mathrm{m}$ to a depth of $33 \mathrm{~m}$.

Layer III A transition layer (from 33 to $45 \mathrm{~m}$ ) over which temperatures increase from $100^{\circ}$ to $1070^{\circ} \mathrm{C}$. The top of this layer will appear resistive as water is flashed as superheated steam; the bottom will appear conductive as temperatures become sufficiently high to activate appreciable conduction in the rock itself.

Layer IV A thin zone (up to $5 \mathrm{~m}$ thick), representing a plexus of molten sills in solid layers.

Layer V A layer with the highest temperature, lowest viscosity, and lowest density of olivine phenocrysts (from $49 \pm 2 \mathrm{~m}$ to $\sim 70 \mathrm{~m}$ ) (modified from Smith et al, 1977).

Layer VI A smooth transition zone, from a low viscosity melt at about $70 \mathrm{~m}$ to a crystaline mush, then into a cooler melt with a lower density of olivine phenocrysts. The uncertainty in the depth to the bottom of this layer $(87 \pm 7 \mathrm{~m})$ is shown by the error bar.

Layer VII Solid basalt with a temperature which, analogous to the calculation of Shaw et al (1977), gradually decreases from $1070^{\circ} \mathrm{C}$ at the top of the layer $(80$ to 95 m) to $700^{\circ}$ or $750^{\circ} \mathrm{C}$ at the bottom of the layer (115 to $120 \mathrm{~m})$.

Figure 2. Proposed Model of Vertical Section Through Kilauea Iki Lava Lake (after Hermance et al, 1979). 


\section{Study}

During March 1980, the US Geological Survey performed a number of electromagnetic sounding and profiling experiments for us in Kilauea Iki. The purpose was to confirm or expand previous data and to determine whether any significant changes in the configuration of the molten lens had occurred since the 1976 experiments. The results indicate that the areal extent of the molten lens has changed little between the two dates (see Figure 3) and that an increase in the resistivity of the melt on the order of a factor of 2 over the time period is suggested.

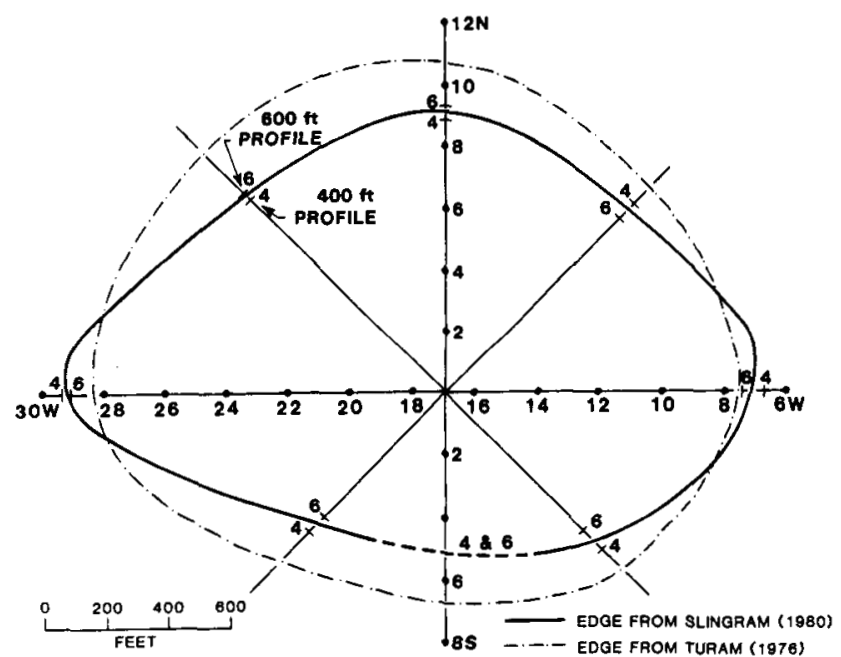

Figure 3. Comparison of Lava Lake Molten Lens Lateral Boundary Measurements in 1976 and 1980 (after Colp, 1982).

In the same time period, Iyer and Stauber of the US Geological Survey conducted an active seismic experiment to detect near-vertical reflections from the top and bottom of the molten lens (Stauber, 1980). Interpretation of their data seems to indicate the presence of three reflectors, but their correlation with discontinuities measured or inferred by other experimenters is speculative.

\section{Study}

University of Texas at Dallas researchers ran an uphole seismic survey through the melt zone and upper crust of the lava lake. Using a large array of stacked vertical and horizontal geophones on a quadrant of the lake surface and a series of explosive detonations at several depths in a freshly drilled borehole extending through the molten lens, they were able to measure the in situ velocity profile shown in Figure 4. Hardee et al (1981) provide a fuller description of this experiment.

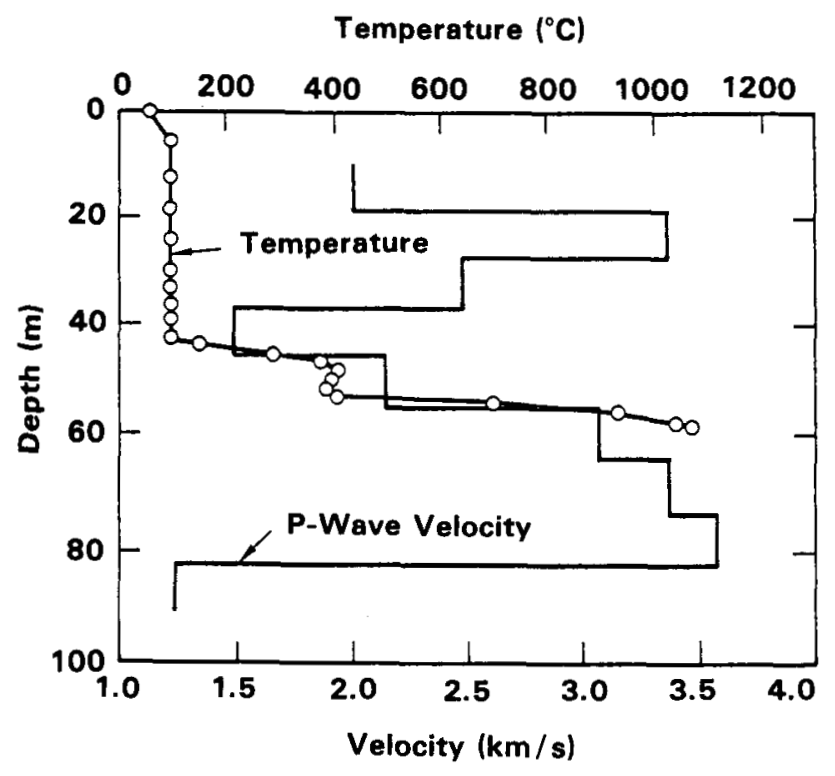

Figure 4. Temperature and Seismic Velocity vs Depth in Kilauea Iki Lava Lake (after Hardee et al, 1981).

\section{Magma Source Location Survey}

We recently completed a Magma Source Location Survey in which over 40 qualified technical and scientific persons in industry, educational institutions, and Federal agencies were interviewed both personally and by mail. Our purpose was to obtain their opinions on the existence of shallow $(<10 \mathrm{~km})$ magma bodies and on methods for locating and defining them. The results obtained were that shallow magma bodies are believed to exist, that existing geophysical sensing hardware and interpretation software are adequate to begin a location program, and that such a program should be a well-coordinated effort using all types of sensing systems producing many data sets. For more detail, see Hardee et al (1982).

\section{Summary}

After $6 \mathrm{yr}$ of limited geophysical experimentation over the known molten-rock lens in Kilauea Iki lava lake, we can say:

- Current geophysical sensing systems have the ability to perform measurements in an analog magma environment. The agreement of the results of the 1976 lateral boundary experiments shown in Figure 1 and the agreement of the lava lake vertical model developed by Hermance et al (1979) in 1976 (Figure 2) with the model developed by Luth (1981) using geochemical data on samples gathered from the 1981 through-melt hole (as shown in Figure 7, later in this report) demonstrates this ability. 
- The magma source environment is very complex, making the unambiguous interpretation of geophysical sensing results quite difficult. An example of the environmental complexity can be seen in the 1981 seismic velocity experimental results (Figure 4). To achieve complete data analysis, in situ values of physical properties (especially electrical conductivity and seismic velocity) of not only the molten rock zone, but also the enclosing fractured hydrothermal region are required.

- All possible geophysical techniques must be used in a magma exploration program. No single technique will provide adequate data. Many data sets from all techniques must be correlated to achieve a suitable solution to the problem of magma location.

- With such an approach, it is highly likely that a satisfactory location of a real magma body can be accomplished.

- We have demonstrated through our experiments over a shallow buried molten-rock body that it is scientifically feasible - according to our stated definition - to locate and define such bodies. Additional research on this subject is certainly required to be able to locate and adequately define a real, deeply buried magma source; however, such research is considered to be part of a follow-on technological (engineering) feasibility study. 


\section{Source Tapping}

\section{State of Deep, Hot Drilling}

No one has drilled into a magma body within the top $10 \mathrm{~km}$ of the surface of the earth; however, holes have been drilled that deeply, and holes have been drilled into molten rock. The USSR is drilling a deep hole into igneous rock in the Kola peninsula and are reportedly at a depth of $10.6^{+} \mathrm{km}$ (Anon, March 1981). A number of deep gas wells in Oklahoma and Texas are being drilled in sedimentary rocks to $10 \mathrm{~km}$ depths (Anon, July 1974).

Geothermal wells in Hawaii and Italy are drilled and completed with bottom hole temperatures on the order of $350^{\circ}$ to $400^{\circ} \mathrm{C}$. The Icelanders have drilled geothermal wells in the Heimaey lava flow with bottom hole temperatures of $914^{\circ} \mathrm{C}$ (Jonsson and Matthiasson, 1974). We have drilled several holes into rock at $1050^{\circ} \mathrm{C}$ in Kilauea Iki including a research well through $33 \mathrm{~m}$ of molten rock at a temperature of near $1100^{\circ} \mathrm{C}$.

\section{Rock Drillability and Borehole Stability Studies}

Significant questions are: Can magma roof-rocks be drilled? Will drillholes through magma roof-rocks be stable and remain open long enough to allow the insertion of energy extraction equipment? Professor M. Friedman and his associates at the Center for Tectonophysics, Texas A\&M University, were contracted to study these questions. This work extended from 1974 to 1980 , at which time funding was continued directly from the Department of Energy.

The objective of this contract study was to determine if magma roof-rocks at in situ pressures and temperatures could be drilled using conventional drill bit types and if the resulting borehole was stable. Four typical magma roof-rock types were selected: Mount Hood andesite, Newberry rhyolite, charcoal granodiorite, and Cuerbio basalt. The test conditions selected were as follows: temperatures up to $1050^{\circ} \mathrm{C}$, confining pressures of 0,50 , and $100 \mathrm{MPa}$, and with rock water contents equal to room-dry and saturated. The results (Freidman et al, 1980) showed that rock strength decreased with increasing temperature, the water-weakening effects increased with increased confining pressure, and, most importantly, all crystalline rocks exhibited brittle failure up to partial melting temperature (see Figure 5). From this study, we conclude that typical magma roof rocks should be drillable with conventional bit types and that the drilling penetration rates should increase as the rocks become hotter.

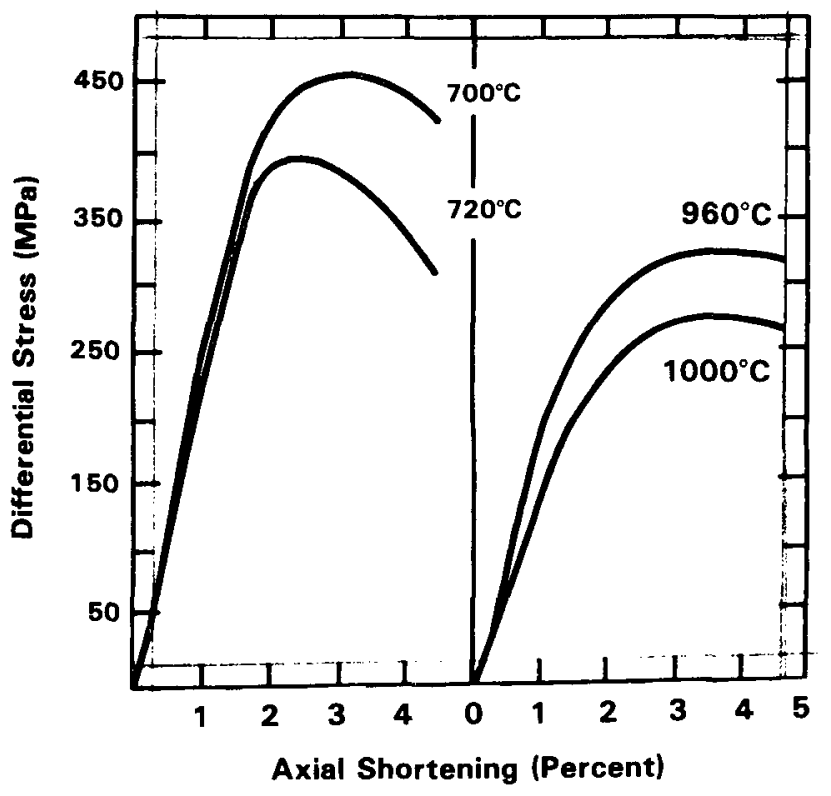

Figure 5. Stress-Strain Curve of Dry Mt. Hood Andesite With Confining Pressure $=100 \mathrm{MPa}$ Showing Brittle Failure (after Friedman et al, 1980).

The results obtained by Friedman et al (1980) also showed that - with one exception - of the three crystalline roof-rocks examined at ratios of horizontal stress to vertical stress of 1.0 or less and borehole temperatures of $900^{\circ} \mathrm{C}$ or greater, all boreholes must be filled with a fluid having a density equal to or greater than water to remain stable to a depth of 10 $\mathrm{km}$. The exception was dry basalt with a stress ratio equal to 0.5 which is predicted to remain stable to depths greater than $10 \mathrm{~km}$ without being fluid-filled. However, if the borehole rocks can be kept at a temperature of $700^{\circ} \mathrm{C}$ or below (a capability we demonstrated in the 1981 lava lake drilling experiment described later), unfilled boreholes in all three roofrocks will remain stable at $10-\mathrm{km}$ depth at a stress ratio of 0.5 . Open (unfilled) boreholes in granodiorite rock will remain stable to that depth even if the stress ratio is as high as 1.0. 


\section{Lava Lake Drilling}

In our original concept of this project, drilling into molten rock was not planned because such drilling would require extensive engineering development and would be very expensive. However, as the project progressed, we did have to get into the subject of molten-rock drilling to support other tasks such as confirmation of the geophysical models of the lava lake and demonstrations of energy extraction concepts.

Our initial concern was that rock at near-molten temperature would display failure mechanisms that might require the use of bits and drilling equipment totally different from conventional types. To investigate this we performed some elementary laboratory tests in which a core of Hawaiian basalt was heated to near-molten temperatures $\left(\sim 1000^{\circ} \mathrm{C}\right)$ and observed the drilling process in a drill press using a carbide-end mill tool. The results showed that the rock failed in a brittle manner with sand-size, incandescent chips being produced. Later, in a series of more sophisticated, but still simple, laboratory tests, the effects of bit load, bit-rotation speed, and rock temperature on hole penetration rate was measured. In all cases, conventional drilling results were observed up to rock melt temperatures.

\section{Program}

The preliminary evaluation of the results from the lava lake geophysical sensing experiments completed in June 1976 left major questions as to the thickness of the Kilauea Iki molten lens that could only be resolved by drilling. Accordingly, we prepared a plan for the 1976 Lava Lake Drilling Program to determine the physical extent, especially the thickness, of the molten lens. The Hawaiian Volcano Observatory personnel who had by far the most experience in drilling Kialauea Iki (Colp and Okamura, 1978) recommended two methods that could be used to readily drill through the liquid lens. First, simply drill through the crust and release the drill string to fall through the melt to the bottom of the lens. Second, drill through the crust just into the melt, raise the bit, chill a solid protuberance underneath the crust, drill the chilled portion, and repeat until penetration through all of the melt.

In August 1976, we used these concepts to determine the thickness of the melt. At about 49-m depth, melt was first encountered. An attempt to push the drill stem down was stopped after moving down about $50 \mathrm{~cm}$; at that point the drill string was frozen in place. After $16 \mathrm{~h}$, the string could be rotated and raised but not pushed deeper. The next attempt, to drill and chill through the melt, also failed because the bit plugged with frozen melt at first contact.

\section{8-79 Program}

We began soon after the 1976 program was finished to design a sophisticated drilling system to continue to drill through an unforeseen solid obstacle in the melt while the drill string was surrounded with molten rock. This sytem, called the Insulated Drill String (IDS), used an uncooled bit capable of drilling solid rock at near-melt temperature. The bit was attached to an insulated drill string with its outer surface at molten rock temperature $\left(>1070^{\circ} \mathrm{C}\right)$. A pressurized, rotating seal-ring arrangement prevented the molten rock under its geostatic pressure from seeping up the solid borehole in the roof rock and freezing against the drill string. A three-wing drag bit, fabricated from Mar-M 905 (a cobalt superalloy commonly used in jet turbine blades), was adequately strong at an operating temperature of $1100^{\circ} \mathrm{C}$. A highpressure air-water mist passing through three nozzles per wing removed the cuttings from the bit area. Laboratory furnace tests demonstrated the satisfactory performance of the bit. The lower portion of the drill string was built with a double concentric tube arrangement. The inner tube, cooled with the airwater mist flow, was strong enough to provide the torque required by the bit. The annular space between the tubes was filled with high-efficiency insulation using both reflective and low-conductivity materials. Laboratory furnace tests demonstrated the satisfactory performance of the design. More detail is given by Colp and Traeger (1980).

All preparations were completed in November of 1978 and drilling commenced late that month. Of the six holes drilled, only one penetrated $6^{+} \mathrm{m}$ of the molten region. The IDS was not used since the indications were that there was no thick accumulation of melt. The results achieved included $100 \%$ core recovery in all six holes, a measurement of the upper crust permeability, several profiles of the upper crust temperatures, and a demonstration of a water-jetaugmented drill bit which will be described later. Neel et al (1979) described this program in more detail.

\section{Experiment}

In April 1981 we performed another drilling experiment based on the previous experience. The major improvements in the 1981 experiment were the use of a smaller diameter drill bit and drilling string, and the newly developed water-jet-augmented core drilling bit described in the following section. The results included the successful drilling of seven holes totaling 701-m 
depth; of this total $105 \mathrm{~m}$ was drilled in molten rock at temperatures greater than $1020^{\circ} \mathrm{C}$. One hole penetrated $29 \mathrm{~m}$ of molten rock at a temperature of $1070^{\circ}$ to $1170^{\circ} \mathrm{C}$. Core recovery was $100 \%$. Hardee et al (1981) provide greater detail.

\section{Water-Jet-Augmented Core Drill Bit}

The concept of this Sandia development is to direct high-velocity and high-volume jets of cooling water from the face of the bit to cool the molten rock ahead of the bit sufficiently so that the rock can be core-drilled without flowing into the bit as a liquid, freezing and plugging the coolant flow. The configuration of this bit is that of a standard, surface-set diamond, face discharge core bit (Figure 6). The modification of the standard bit consists of the fabrication of venturi nozzles in place of the normal face discharge holes. Eighty percent of the coolant flow down the drill string is directed through the nozzles at high velocity. The high-velocity water jets not only cool the bit and remove the cuttings, but they also chill the melt into a porous plastic immediately ahead of the bit. The water-jet nozzles are designed to supply sufficient water to maintain a stable hole and allow rapid drilling rates while at the same time avoiding steam-explosion hazards or hole failures that could occur with excessive downhole water flow rates.

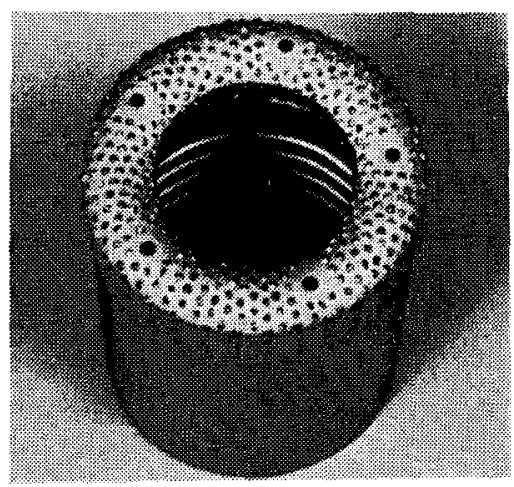

Figure 6. Water-Jet-Augmented Core Drill Bit Showing Face-Discharge Coolant Nozzles.

Drilling rates as high as $20 \mathrm{~m} / \mathrm{h}$ were commonly observed during drilling in the lava lake (Hardee et al, 1981). Regions of the lake with temperatures in excess of $1070^{\circ} \mathrm{C}$ were cored as rapidly as were the cooler upper crust regions. Where local veins of highpercentage melt fraction were encountered, the melt was rapidly chilled into a glassy rubble by the highvelocity jets.

\section{Summary}

Our laboratory experimentation has demonstrated that:

- Typical magma roof-rocks at in situ pressures and temperatures to $10-\mathrm{km}$ depth exhibit brittle failure up to melt conditions and should be drillable with conventional bit types.

- Drilling penetration rates should increase as rock temperatures increase.

- Boreholes in magma roof-rocks at in situ conditions to $10-\mathrm{km}$ depth can be kept open and stable by proper cooling and filling.

Our experience in drilling in the lava lake environment, which presented problems similar to those expected in deep magma drilling, has taught us the following:

- A drill bit with cooling channels optimized for high-velocity coolant flow is imperative to successfully drill though the highly fluid veins of high glass-content melt frequently encountered, and into the melt zone with rock temperatures of $1020^{\circ}$ to $1170^{\circ} \mathrm{C}$, and to redrill melt that has flowed back uphole.

- Drill bit wear rate in the melt zone was minimal and no bit matrix distress or diamond fracturing was observed if a continuous flow of coolant was maintained.

- Holes drilled into the melt zone could be kept open and stable as long as desired by cooling with a stream of water from the surface. If remelting of the hole was desired, it could be done by decreasing the water flow. Redrilling of the collapsed, remelted hole was easily accomplished using the water-jet-augmented bit. The reopened hole could be kept open and stable by reintroducing the coolant flow from above.

- Successful drilling in the melt region (T $>1020^{\circ} \mathrm{C}$ ) requires a continuous supply of highpressure, high-velocity coolant. Any interruption ( $>$ a few minutes) of coolant flow down the drill string while drilling results in hole loss at best and bit and drill string loss as well at worst. A redundant cooling system would be required for deep drilling. 
- On-site petrologic analysis of core samples to advise the driller of melt content is required. This real-time information is necessary so that the driller is always aware of the bottom-hole conditions.

- The highly fractured crust overlying the hightemperature zone prevented any coolant return. Specialized casing and cementing methods will have to be developed for deep holes if drilling fluid return is required.

- Collapse of the drillhole sidewall in the hot, highly fractured, overlying crust with wedging in place and loss of the drill string occurred during our 1978-79 operation. Cementing of the formation is not possible because of its temperature. About the only solution is to concurrently drill a casing over the advancing core barrel.
- As part of the national Continental Scientific Drilling Program, a workshop to discuss drilling at magma depths was held (Varnado and Colp, 1978), and a system study of drilling considerations in the magma environment has been conducted (Traeger et al, 1981). These efforts identify some of the engineering research and development needed to proceed with the actual drilling into a magma source.

- We have demonstrated through laboratory experiments and field practice that there are no insurmountable theoretical or physical barriers to prevent drilling into a magma deposit; therefore, we have concluded that magma tapping is scientifically feasible. However, as system studies have shown, considerable engineering research and development work is required before access to real magma can be accomplished. 


\section{Magma Characterization}

\section{State-of-the-Art}

At the Sandia/USGS Magma Workshop in March 1975 , a group of 30 experts in a variety of fields related to magma research was convened. Twelve members of this group addressed the state-of-the-art in chemical and physical properties of magma. The consensus was that knowledge of these properties is essential for evaluating the feasibility of extracting energy directly from magma bodies. Finding a magma body, drilling and emplacing an energy extraction system in it, and extracting the energy all require thorough knowledge of the various physical and chemical properties of molten rock. Of the 26 properties of magma considered by this group, 13 were ranked as poorly known. A more detailed description is found in Colp et al (1975).

\section{Volcanic Gases Studies}

Fugutive gases significantly affect the properties of in situ magma and its compatibility with engineering materials. Consequently, considerable effort has been spent during the project on models of in situ gas contents of magmas based on observed compositions of emitted volcanic gases. Most of the data used have been gathered by other investigators and shared with us. Approximately 150 samples have been restored to in situ conditions. The results of gas studies for $\mathrm{Mt}$. Etna (Gerlach, 1979), Kilauea (Gerlach, 1980A), Erta Ale lava lake (Gerlach, 1980B), Nyiragongo lava lake (Gerlach, 1980C), Surtsey volcano (Gerlach, 1980D), Ardoukoba (Gerlach, 1981A), and Merapi volcano (Le Guern et al, 1982) have been published. This information provides an adequate data base for materials compatibility investigations in $\mathrm{C}-\mathrm{O}-\mathrm{H}-\mathrm{S}-\mathrm{Cl}$ systems typical of mafic and andesitic lavas.

\section{Magma Petrology Studies}

The work on the petrology of igneous rocks in this project has been confined to studies on core samples obtained from Kilauea Iki lava lake drilling programs. These studies have three direct applications to the project:

- To constrain and check geophysical models of the lava lake

- To provide information for energy extraction experiments at that site

- To examine the geochemical responses of magma and hot rock to thermal perturbations caused by drilling fluids and energy extraction, and to compare these with the effects of natural cooling processes

During the 2-1/2 yr of petrologic effort, samples from Kilauea Iki have been the subject of intensive study, using the automated electron microprobe as the key analytical tool. Forty-nine samples from four holes (three penetrating into the magmatic regime drilled in 1978) and 34 samples from one hole through the magmatic zone (drilled in 1981) have been analyzed.

A summary of our analyses of the Kilauea Iki cores indicates that the evolution of the liquid phase shows a continuous compositional change from basaltic to rhyolitic. The liquid composition reflects the crustal temperature gradient. The evolution of the mineral assemblage shows that chemical equilibrium is closely approached in the magma zone. Extensive disequilibrium is indicated in the transition zone and in the upper crust.

Based on mineral-liquid relationships, it appears that the maximum magma temperature was less than $1170^{\circ} \mathrm{C}$. It is clear that gravitational settling is important in the early history of cooling of a magma body; however, in situ crystallization is dominant during the final stages of cooling at the present time.

Figure 7 depicts our model of the vertical structure of the lava lake based on the 1981 core study.

A series of reports by W. C. Luth and others describing the petrologic study of the lava lake cores will appear in future issues of the Journal of Volcanology and Geothermal Research.

\section{Kilauea Iki Vertical Structure April 81}

$\begin{array}{rll}0-43 \mathrm{~m} & \text { Upper Crust } & 100^{\circ} \mathrm{C} \\ 43-57 \mathrm{~m} & \begin{array}{l}\text { Sub-Solidus Upper } \\ \text { Crust }\end{array} & 100^{\circ}-960^{\circ} \mathrm{C} \\ 57-61 \mathrm{~m} & \begin{array}{l}\text { Upper Magmatic } \\ \end{array} & \\ & \text { Transition Zone } & 960^{\circ}-1070^{\circ} \mathrm{C} \\ 61-90 \mathrm{~m} & \text { Magma } & 1070^{\circ}-1170^{\circ} \mathrm{C} \\ 90-92 \mathrm{~m} & \begin{array}{l}\text { Start of Lower } \\ \text { Transition Zone }\end{array} & 1020^{\circ}-1070^{\circ} \mathrm{C}\end{array}$

Figure 7. Model of Kilauea Iki Lava Lake Vertical Structure Based on 1981 Core Sample Study (after Luth, 1981). 


\section{Magma Simulation Facility}

The need for a high pressure $(60 \mathrm{kpsi})$, hightemperature $\left(1600^{\circ} \mathrm{C}\right)$ facility for experimenting with large samples of molten rock was recognized immediately after the Magma Workshop. The facility needed to have unique pressure, temperature, and sample volume features for making basic properties measurements (viscosity, electrical conductivity, thermal conductivity), and material compatibility determinations with various molten rock samples at simulated in situ magma conditions. Although we started design of the facility in April 1975, the complete system was not accepted until April 1979 because of design problem delays and problems in material availability.

The facility has a sample chamber with a uniform hot zone $10 \mathrm{~cm}$ in diameter by $10 \mathrm{~cm}$ in height with a volume of $0.8 \mathrm{~L}$. The inert gas working pressure is 60 kpsi supplied by a two-stage intensifier. The pressure vessel is $56 \mathrm{~cm}$ (22 in.) in diameter, $109 \mathrm{~cm}$ (43 in.) high, and weights approximately $2273 \mathrm{~kg}(5000 \mathrm{lb})$. Operation of the facility and data recording are computer-controlled. Figure 8 shows an artist's drawing of the components of the facility. It has been operational since April 1979 and approximately 32 experiments have been performed at various pressures and temperatures. More detailed description can be found in Wemple, 1981.

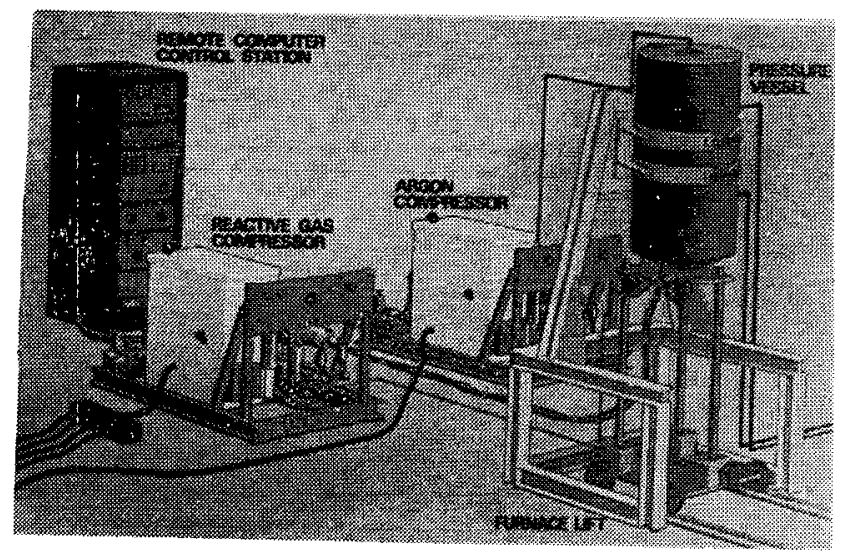

Figure 8. Sandia Magma Simulation Facility. Experiment capabilities: temperature to $1600^{\circ} \mathrm{C}$; pressure to $4 \mathrm{kbar}(60$ $000 \mathrm{psi}$ ); chamber volume $=0.82 \mathrm{~L}$.

\section{Heat-Transfer Studies}

We used the Magma Simulation Facility (described above) to investigate the effect of water content on convective heat transport in molten basalt at magma in situ conditions. The experiments were run on Cuberio basalt at two water contents: dry and 3 w/o water $(65 \%$ water saturation at liquidus temperature). Figure 9 shows the results we obtained at 2 kbar pressure, corresponding to a magma burial depth of $7.5 \mathrm{~km}$ (Dunn, 1981). We observed significant convection above $1200^{\circ} \mathrm{C}$. The experiment results gave excellent agreement with a calculation from a Sandiadeveloped 2-D axisymmetric, finite-element computer program. The higher water content resulted in a $35 \%$ greater convective heat-transfer rate. The results of this work provide increased confidence in the prediction of transport in large magma bodies.

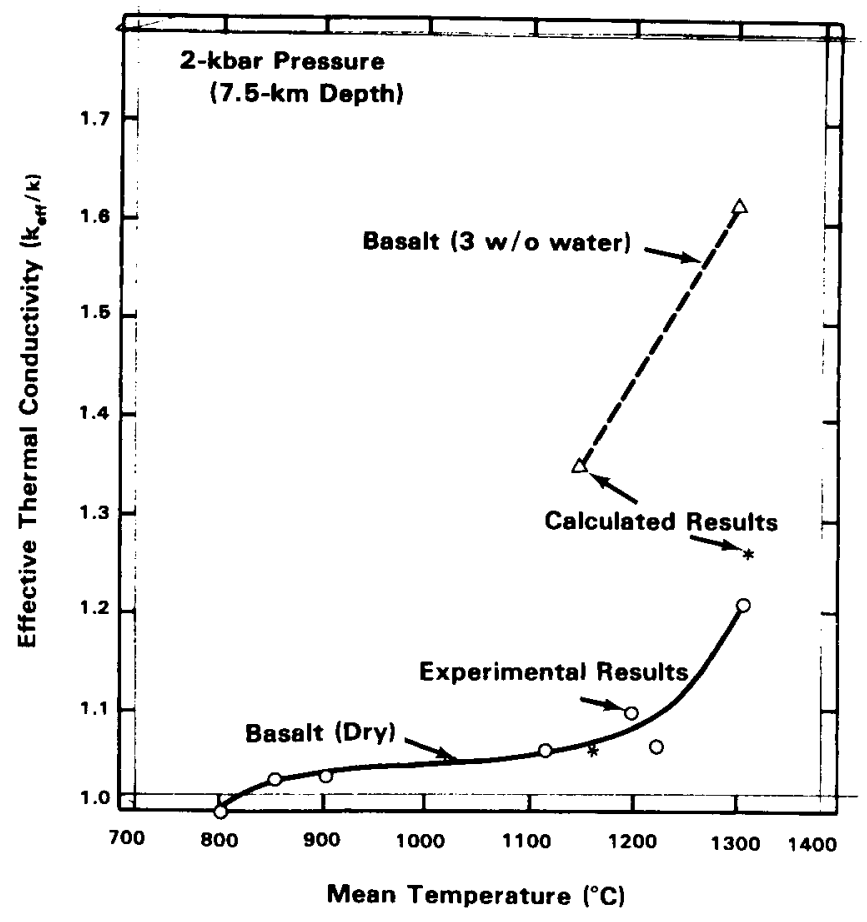

Figure 9. Magma in situ Convection Results Using Cuberio Basalt at 2-kbar Pressure (after Dunn, 1981).

\section{Viscosity Studies}

We began development of a falling sphere viscometer to use in the Magma Simulation Facility to measure in situ values of molten rock viscosity. The basic concept employed in the electromagnetic viscometer is a tuned circuit (transformer-driven at its characteristic resonant frequency). The secondary windings of the transformer are wound on the sample crucible. When the metallic sphere travels down the vertical centerline of the windings, the resonance of the coil is disturbed and an output signal is produced. Knowing the spacing between detection coils and the travel time, viscosities can then be calculated.

In order to more fully understand the passage of a metal sphere through molten rock, a real-time $\mathbf{x}$-ray technique was developed. Visual observation of the sphere falling through the melt was desired to observe 
void formation. Also verification was sought for the assumption that the greatest deviation in secondary coil output voltage occurred when the falling sphere was in the center of the coil. Continued development of this technique revealed that it could be used as a viscosity measurement method and in studies of bubble and void formation, crystal migration, and heat transfer by using various image-enhancement methods.

A continuous $300 \mathrm{kV}$ x-ray source in the Sandia Nondestructive Testing Laboratory was used for this technique. The $\mathbf{x}$-ray source has sufficient power to penetrate the vertical tube furnace,crucible wall, magmatic rock, and metallic sphere. The resulting radiograph is detected on a fluorescent screen that is viewed by a TV camera. The TV image is then displayed on a standard monitor and also recorded on videotape. Data are obtained directly from the TV monitor when the videotape is replayed by timing the passage of a sphere moving down the crucible axis that was divided into 11 increments, each 1 ball diameter in height.

Observation of the passage of many spheres revealed that temperature uniformity, bubble formation, and fluid-closure patterns in the wake of the falling sphere drastically effect the apparent viscosity data. Additional causes of obviously invalid viscosity determinations were identified. For example, if the sphere passed through the magmatic basalt although not near the centerline of the crucible as intended but instead near the crucible wall, the measured velocity was much lower and the apparent viscosity much higher. Another observation was that sufficient time must be allowed for temperature equilibration after adding powdered sample material to an existing melt.

Data taken for the initial development of the EMV and $x$-ray viscometers were published in Wemple et al (1980). A summary data plot from that report is shown in Figure 10. The report very explicitly states that these values can only be considered "apparent viscosities" because of the non-Newtonian nature of the sample materials.

Data taken by Ryan and Wemple (Colp, 1982) are shown in Figure 11 and again must be considered qualitative, but are an improvement over the previous data in the referenced report because of the effort expended in reducing the formation of bubbles.

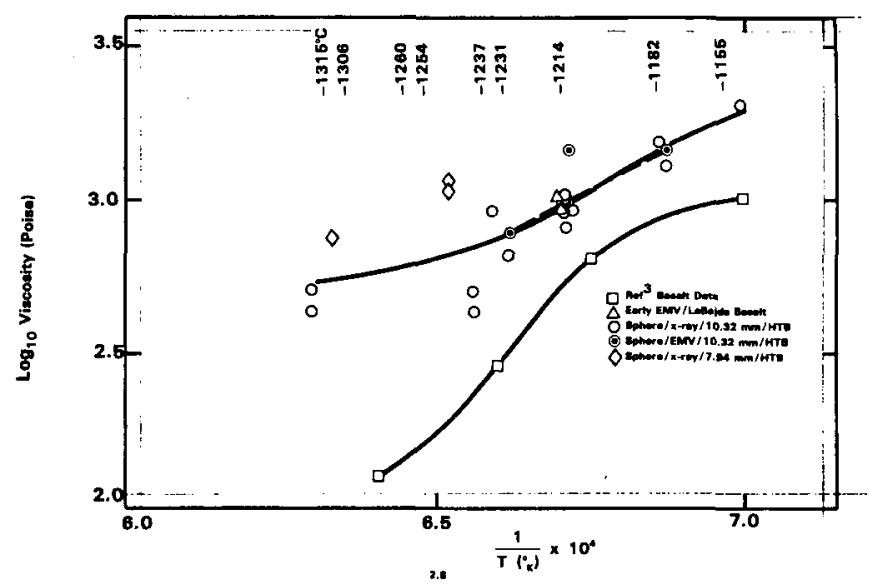

Figure 10. Viscosity Data Summary - Various Basalts (1 bar) (after Wemple et al, 1980).

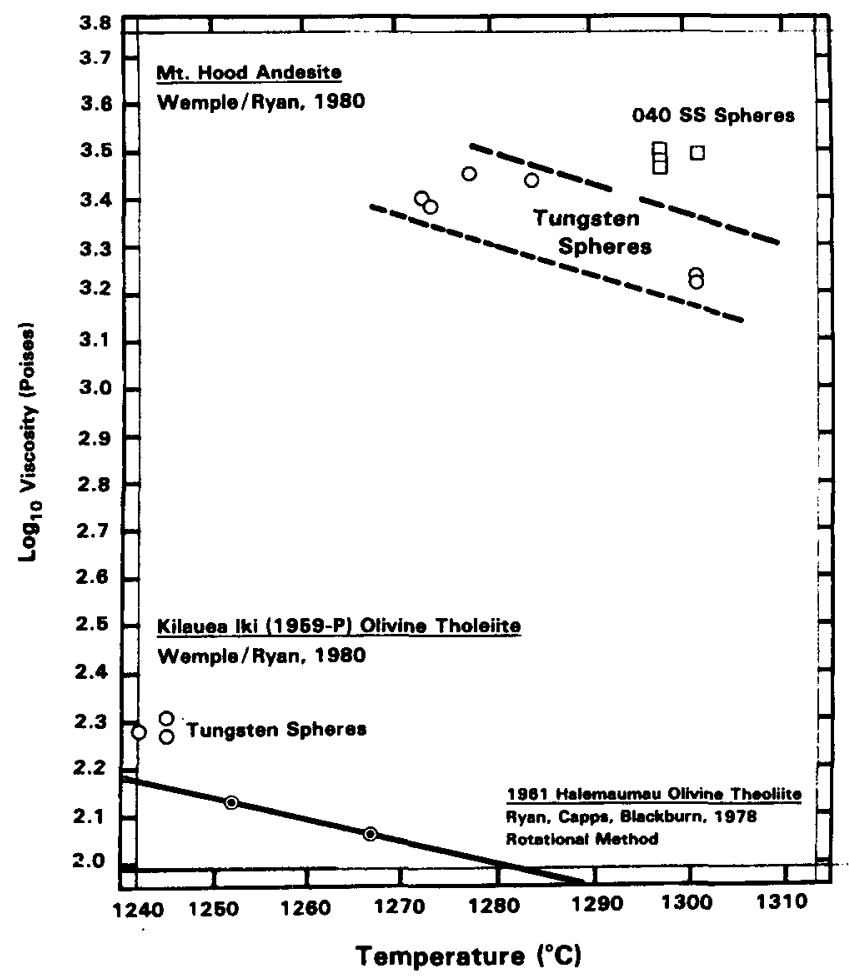

Figure 11. Viscosity Data Summary - With Reduced Bubble Formation (after Colp, 1982). 


\section{Summary}

Our efforts on the Magma Characterization task have produced the following results:

- The gas composition of in situ magmas can be modeled from surface emissions of volcanic gases. These modeled compositions can be used in magma property studies and magma/material compatibility experiments.

- Petrologic/geochemical studies have provided insights on the cooling history of totally enclosed molten-rock bodies that are useful in predicting magma body lifetimes.

- A unique Magma Simulation Facility for in situ pressure and temperature experiments was designed, built, and put in operation. In addition to being used for our own experiment studies, this facility is available for use by other experimenters.

- Experiments run in the Magma Simulation Facility at in situ conditions have shown that an increase in the water content of molten basalt results in a $35 \%$ greater convective heat-transfer rate.

- An electromagnetic falling-sphere viscometer that can be used in the Magma Simulation Facility at in situ conditions has been built and demonstrated. This instrument is the first of a series that could be developed for measuring various properties of molten rock at magma in situ conditions.

- The results of calculational, field, and laboratory studies lead us to conclude that current data on magma properties is marginally adequate for the purpose of engineering feasibility studies and that a facility and some techniques exist for obtaining additional data required. Our results show that the conclusion that magma characterization is scientifically feasible is justifiable. Additional research is required on the characterization of properties, particularly the probable overpressure from the higher volatile content, of the more silicic (rhyolite) systems as part of any follow-on engineering feasibility assessment. 


\section{Magma/Metal Compatibility}

\section{Introduction}

The ability to build a heat-transfer device that can be inserted directly into a magma source is critical to the successful use of magma energy. The materials used for building a heat exchanger must retain their physical and structural properties sufficiently to allow it to perform for many years if the installation is to have an economic value.

The components of a magma energy heatextraction system will experience a variety of three general environments. Each represents different conditions and problems as shown in Table 3.

\section{Table 3. Magma/Metal Environments}

\begin{tabular}{|c|c|c|}
\hline $\begin{array}{l}\text { Environment } \\
\text { (Location) } \\
\end{array}$ & Conditions & Problems \\
\hline 1. Near Surface & $\begin{array}{l}\text { Low temperature } \\
\left(150^{\circ} \mathrm{C}\right) \text { oxidizing, } \\
\mathrm{H}_{2} \mathrm{O} \text { rich gas }\end{array}$ & Oxidation corrosion \\
\hline $\begin{array}{l}\text { 2. Hydrothermal } \\
\text { Region }\end{array}$ & $\begin{array}{l}\text { Moderate }\left(150^{\circ} \text { to }\right. \\
\left.500^{\circ} \mathrm{C}\right) \text { tempera- } \\
\text { ture, oxidizing, } \\
\text { corrosive hydro- } \\
\text { thermal brines }\end{array}$ & $\begin{array}{l}\text { Oxidation and brine } \\
\text { corrosion }\end{array}$ \\
\hline 3. Magma & $\begin{array}{l}\text { High }\left(>1150^{\circ} \mathrm{C}\right) \\
\text { temperature, re- } \\
\text { ducing, high sulfur }\end{array}$ & $\begin{array}{l}\text { Sulfidation corrosion, } \\
\text { thermal degradation, } \\
\text { metal dissolution }\end{array}$ \\
\hline
\end{tabular}

Since environments 1 and 2 are being investigated extensively as part of the development of hydrogeothermal energy resources, we elected to concentrate our efforts on the magma environment.

A magma heat exchanger may be exposed to two different thermal regimes in its lifetime long-time (30 yr) normal operation and short-time $(\sim 400 \mathrm{~h})$ emergency excursion. In normal operation the flow of the energy-extracting heat-transfer medium will control metal temperatures to $300^{\circ}$ to $600^{\circ} \mathrm{C}$. However, an emergency shutdown of the heat-transfer fluid flow will allow metal temperatures to reach those of the ambient magma, $1000^{\circ}$ to $1100^{\circ} \mathrm{C}$. Current materials are available to meet the normal operating conditions. Our research has been directed toward finding materials that can withstand emergency conditions.

\section{Magmatic Gas Compatibility}

Our initial research was to study the effects of magmatic gases on selected metals by inserting them into natural fumaroles on Kilauea volcano. Results indicated that pure iron, pure nickel, and ferritic 446 stainless steel were extremely susceptible to attack. Molybdenum, tungsten, and the nickel-based superalloy Udimet 700 acquired a uniform dark corrosionproduct layer. Tantalum and its nickel-based superalloy Inconel 718 appeared to be inert (Colp et al, 1976).

\section{Molten Lava Compatibility}

Concurrent with the field exposures to fumarolic gases, we began a laboratory study of metal compatibility with molten degassed Hawaiian tholeiite lava and molten rhyolite obsidian. These tests were run at atmospheric pressure. Our data from the basalt tests indicated that nickel- and cobalt-based alloys may have special qualities enabling survival in the magma environment. Udimet 700, Inconel 718, and Hastelloy $\mathrm{X}$ were samples that appeared to give promising test results. Metallographic examination of exposed samples showed that molten rhyolite, even with some water present, is a more benign environment than the tholeiite basalt (Sallach, 1975; Colp and Brandvold, 1976).

\section{Pure Metal Compatibility Tests}

In 1978, a series of laboratory screening tests on the compatibility of 15 pure metals exposed to a simulated magma environment for times up to $96 \mathrm{~h}$ was begun. The chemical characteristics of magmatic gases used in our tests were obtained from the work of Gerlach described in the preceding chapter of this report. The critical feature of magmatic gases, from the point of view of material incompatibility, are their $\mathrm{O}_{2}$ and $\mathrm{S}_{2}$ fugacities which are conducive to oxidation and sulfidation of most metals at magmatic temperatures. Molten tholeiitic basalt at $1150^{\circ} \mathrm{C}$ was used for the tests.

We observed a wide range of reactivity using techniques of optical microscopy, scanning electron microscopy, dispersive $x$-ray energy analyses, and, in some cases, electron microprobe analysis. The conclusions reached were: iron, nickel, and cobalt cannot be used without alloying because of the extensive liquid 
sulfide formation and high reaction rates. Chromium appears to be the most beneficial addition. Molybdnum has a high degree of resistance to the environment as long as the oxygen fugacity remains low. Rhenium showed outstanding corrosion resistance but is expensive. Platinum is the only precious metal tested that can survive the environment. Douglass and Healy $(1979,1981)$ provide more detail on this work.

\section{Alloy Metal Compatibility Tests}

Following the pure-metal screening experiments, similar work on alloyed metals was started. One goal of alloying element additions is to form oxides in the low-oxygen pressure of the magma environment in order to provide a protective oxide layer that reduces corrosion rates. Another objective is to overcome a problem more important than rapid reaction rates, preventing the formation of low-melting eutectics between the metals and their sulfides.

Certain trends have become apparent from work on stainless steels:

The chromium content of both ferritic and austenitic stainless steels is the most important factor in providing corrosion resistance. However, there appears to be a critical value in the vicinity of $23 \%$ to $25 \%$ that changes with time. Corrosion tests must be run for sufficient time to establish the true steady-state reaction products; the products forming at longer times (e.g., $400 \mathrm{~h}$ ) are more deleterious than those formed at shorter times.

There appears to be a difference in behavior between commercial ferritic stainless steels and high-purity $\mathrm{Fe}-\mathrm{Cr}$ binary alloys. The difference is attributed to the presence of both silicon and maganese in the commercial alloys.

There may be a synergistic effect of chromium and nickel in the austenitic alloys in providing corrosion resistance. The role of silicon and maganese in Type 310 stainless steel must be evaluated. Type 310 is by far the most corrosion-resistant alloy of any of the commercial stainless steels.

Although only preliminary data are available, it appears that molybdenum is a beneficial addition at the $6 \%$ level but not at the $2 \%$ level.

Iron-chromium alloys with sufficient chromium $(24 \%)$ are more corrosion-resistant than cobaltchromium, which is more corrosion-resistant than nickel-chromium.

(For more information on this work, see Colp (1979a) and Douglass and Healy (in publication).)

Continuing experiments used similar equipment, environments, and times of exposure as did those previously performed. The results of this work are reported in Ehrlich and Douglass (1982). Their conclusions are:

The corrosive effect of molten basalt and/or magmatic volatiles of basaltic lavas was studied in alloy systems. The alloys that provided the highest degree of corrosion-resistance were ternary alloys containing molybdenum and chromium. The result of these alloying additions was a transition from the deleterious effects of internal sulfidation to the formation of a protective chromiumoxide external scale. The more stable molybdenum and chromium sulfides also formed.

The binary alloys containing molybdenum did not exhibit adequate corrosion resistance because of extensive sulfidation reactions and the formation of liquid base-metal sulfides. Alloys containing a high enough molybdenum content (10 to 15 w/o for iron- and nickel-based alloys and 5 to 10 w/o for cobalt-based alloys) formed a more stable $\mathrm{MoS}_{2}$ and corroded less.

\section{Summary}

- Engineering materials used to extract energy from magma will be exposed to three natural environments: near-surface, hydrothermal, and magma. They will be subjected to two operational thermal environments: normal $\left(300^{\circ}\right.$ to $600^{\circ} \mathrm{C}$ ) temperatures for the plant lifetime and emergency $\left(700^{\circ}\right.$ to $\left.1100^{\circ} \mathrm{C}\right)$ temperatures for a few hundred hours.

- Currently available materials can meet the normal thermal environment adequately.

- Laboratory corrosion studies show that we know how to select alloyed metals that can perform adequately in the in situ basaltic magma environment under emergency conditions.

- Based on our results, the conclusion is reached that engineering material/magma environment compatibility is scientifically feasible. Additional research on the effects of the probable higher halogen contents of silicic magma systems is required for engineering feasibility assessment. 


\section{Energy Extraction}

\section{Introduction}

Molten magma bodies offer a source of highquality, pollution-free thermal energy. We have considered a number of schemes for energy extraction from magma, including thermionics, thermoelectrics, steam generation for conversion to electricity, hydrogen production, and generation of synthesis gas. We chose the last three extraction schemes (steam, hydrogen, and synthesis gas) for study in this project since thermodynamics and surface processing technologies are well defined. Steam production for electric power generation is the simplest and most obvious method for extracting energy from magma. We have investigated to a lesser degree the use of magma resources for production and refinement of fuels. This alternative is particularly attractive for two reasons:

- The major conventional energy options for the future (coal and nuclear) are better suited for electricity generation.

- High quality liquid and gaseous fuels are most desirable for their versatility as energy forms that can be stored, transported efficiently, and used to produce a wide variety of important chemicals.

\section{Theoretical and Computational Studies}

Our early energy extraction calculations examined energy-transfer rates to a closed heat-exchanger system by conduction heat-transfer through magma (Hardee, 1974). While such conduction-dominant energy extraction rates were attractive at early times, the rates decayed with time and amounted to an average of only $1 \mathrm{~kW} / \mathrm{m}^{2}$ of heat exchanger area over the expected 30-yr plant lifetime (Hardee, 1974; 1981). We recognized that acceptable energy-extraction rates could be achieved only by convection heat transfer in the magma, or with open heat-exchanger systems in which the heat-transfer working fluid mixed directly with the magma.

We performed convection calculations for superliquidus magmas that behaved as simple Newtonian liquids and exhibited attractive heat-transfer rates (Hardee and Larson, 1977; Hardee, 1981 and 1979a). Experiments in furnace melted samples of lava (Hardee, 1975; Fewell et al, 1975; and Hardee, 1981), and field experiments at eruption sites (Hardee, 1979b and 1980 ) confirmed the convection calculations. Convective heat transfer for basaltic and andesitic magma bodies appears to offer attractive energy extraction rates for closed heat-exchanger systems (Hardee, 1981).

It is important to recognize several basic facts about magma convective heat extraction. First, the heat exchanger and its working fluid operate at an intermediate temperature $\left(300^{\circ}\right.$ to $\left.600^{\circ} \mathrm{C}\right)$, well below the magma temperature $\left(900^{\circ}\right.$ to $\left.1400^{\circ} \mathrm{C}\right)$. Not only is it desirable for the heat-transfer process to maintain a significant temperature drop between the heat exchanger and the magma but, if the working fluid were heated to higher, near-magma temperatures, the working fluid would be too hot at the surface to use in conventional turbines. A second important point is that magma must not necessarily be convecting on its own to be of use. It is only necessary that convection be induced at the heat-exchanger surface as a result of emplacement of the heat exchanger in the magma. Finally, it should be observed that at low convection rates the crust that forms on the heat-exchanger surface becomes very thick or large in diameter. As a result, this geometrical increase in surface area for convection partially compensates for the lower convective heat transfer. This results in weak convection still being attractive when viewed in terms of the potential heat extraction per unit area of borehole (Hardee, 1981).

Calculations and experiments in the subliquidus temperature range were made when we recognized that magmas would likely exist at liquidus or subliquidus temperatures rather than superliquidus temperatures (Hardee and Dunn, 1981). Analytical convection solutions were developed for the non-Newtonian fluid behavior of subliquidus magmas and these calculations were compared with laboratory experiments in furnace-melted samples of lava. The subliquidus heattransfer rates were still attractive for basaltic and andesitic magmas, largely because of the geometrical area enhancement of the thick crust on the heatexchanger surface (Hardee, 1981).

An open heat-exchanger system in which the heattransfer working fluid mixes directly with the magma is a useful technique for greatly increasing energy extraction rates. In this process a rubbled permeable 
bed of hot solidified magma is produced around the heat exchanger. The eventual large extent of the rubbled bed results in a large area of contact with the surrounding molten magma. This in turn leads to large energy-extraction rates in terms of the borehole surface area. Calculations and laboratory experiments indicated that open heat-exchanger systems should have energy extraction rates 10 to 100 times greater than closed heat-exchanger systems (Hardee, 1979a). An open heat-exchanger system that was field tested in Kilauea Iki lava lake in 1981 (Hardee et al, 1981) produced steady energy-extraction rates of $180 \mathrm{~kW} /$ $\mathrm{m}^{2}$ and transient rates of $950 \mathrm{~kW} / \mathrm{m}^{2}$ (Hardee et al, 1981; Larson et al, 1981). Open heat exchangers not only offer very attractive energy extraction-rates but also greatly extend the range of exploitable magma bodies.

\section{Initial Computational Studies}

Our initial efforts on the energy-extraction task were a series of computational studies on possible heat-extraction rates (per unit area of heat-exchanger surface) from a magma reservoir, reported by Hardee (1974). Estimates of these heat-extraction rates ranged from a low of $1 \mathrm{~kW} / \mathrm{m}^{2}$ to a value of $175 \mathrm{~kW} / \mathrm{m}^{2}$, depending upon the assumptions made about the source conditions. The low figure corresponded to the rate expected from a conduction-dominated source, considering a $30-\mathrm{yr}$ plant life. The $175 \mathrm{~kW} / \mathrm{m}^{2}$ figure was typical of a magma source with considerable convection. For comparison, published extraction rates for solar collectors are $0.15 \mathrm{~kW} / \mathrm{m}^{2}$ (daily average) and typical rates for coal-fired boilers are 100 to $200 \mathrm{~kW} / \mathrm{m}^{2}$.

\section{Molten Lava Single-Tube Boiler Experiment}

One of the first laboratory experiments we performed in the project was the Molten Lava/SingleTube Boiler experiment shown in Figure 12.

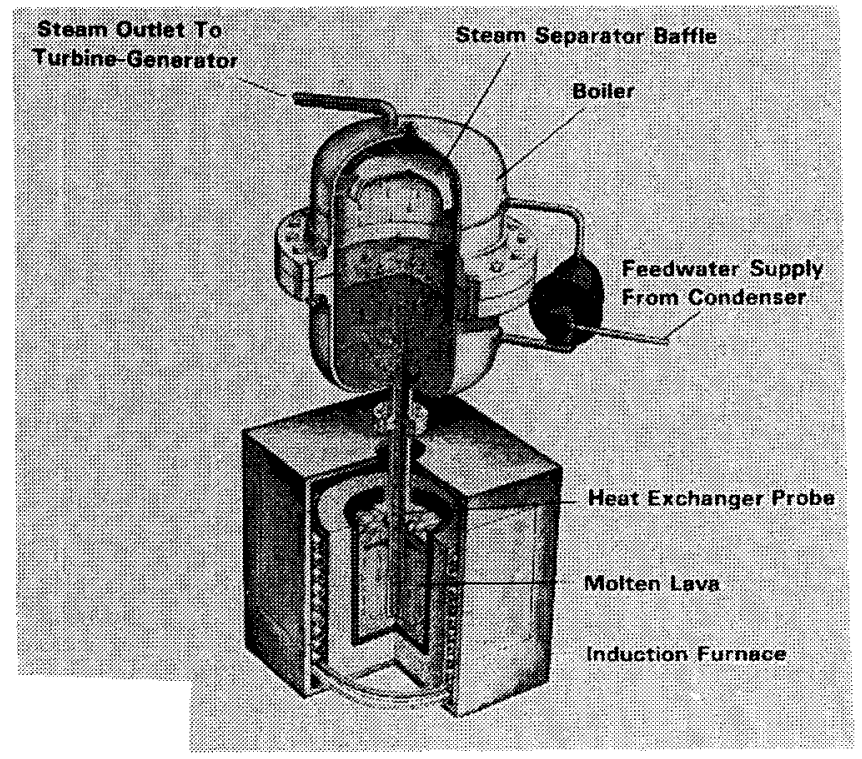

Figure 12. Schematic of the Molten Lava/Single-Tube Boiler Experiment.

The test purposes were:

- To demonstrate that useful amounts of thermal energy could be extracted from a molten lava heat source whose temperature was well in excess of the melt temperature of the heat exchanger.

- To measure heat-extraction rates and the amount of convection in the molten lava and to compare these values with previous calculations.

- To verify calculations for the thermal transient during insertion of the heat exchanger into the molten lava and to show that the resulting stresses and temperatures were not excessive during the transient.

- To show that corrosion of the heat exchanger in the molten lava was not an insoluble problem.

The test was highly successful. Two runs were made: the first was of 3 -h duration and the second was of 24-h duration. Corrosion of the heat exchanger 
was not a problem, even though the temperature of the molten lava was in excess of the melt temperature of the steel heat exchanger. (Temperature in the molten lava core was measured as in excess of $1450^{\circ} \mathrm{C}$ and estimated to be as high as $1650^{\circ} \mathrm{C}$.) A solidified lava crust formed next to the heat exchanger as predicted (see Figure 13). Energy balance calculations verified that the solidified lava crust next to the heatexchanger surface had a thermal conductivity of 0.005 to $0.006 \mathrm{cal} / \mathrm{cm}-\mathrm{s}^{\circ}{ }^{\circ} \mathrm{C}$ and that the effective thermal conductivity of the molten-lava core was about twice this value. The test data allowed a good check to be made on previous convection calculations for the molten-lava core. The surface temperature transient on the heat exchanger was measured and agreed reasonably well with predictions. High-quality steam was produced (i.e., qualities of $99^{+}$percent). Heat extraction rates of 179 to $314 \mathrm{~kW} / \mathrm{m}^{2}$ were typically measured during the test. Design of the experiment is reported in Fewell et al (1975) and Davis and Mottern (1975). The results achieved are reported by Hardee and Fewell (1975).

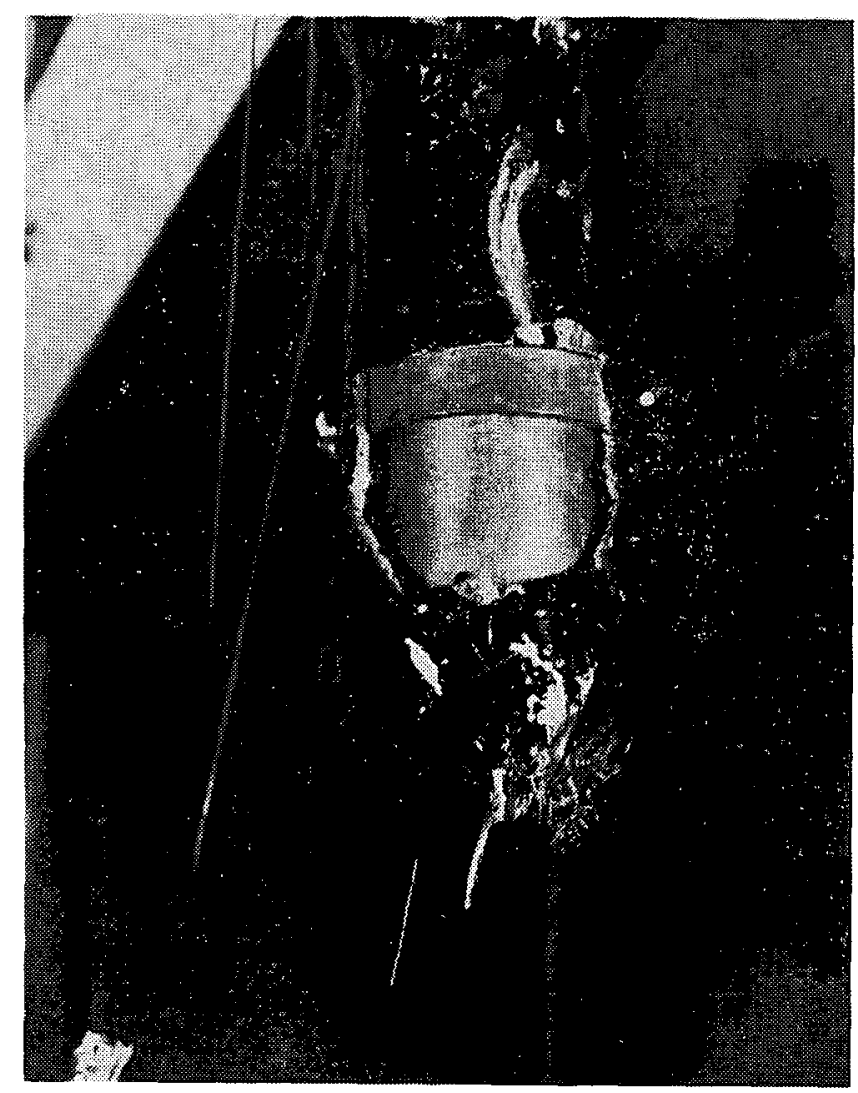

Figure 13. Single-Tube Boiler as Removed From Molten Lava Showing Solidified Lava Crust Encasing Stainless Steel Boiler Tube.

\section{Long-Tube Heat-Exchanger Facility}

As we examined the concept of a long single-tube boiler to produce steam from a buried magma source, it became apparent that the great vertical distances involved and the resulting hydrostatic head would cause large pressure variations. These variations could extend from atmospheric to above the critical pressure of water. Examination of the literature revealed that little work had been done to characterize heatexchangers with large internal-pressure variations. We decided to design and construct a facility to study the heat transfer and mechanics of boiling in long (20 $\mathrm{m})$, single-pass, counterflow heat exchangers.

The facility consists of a closed-loop counterflow heat exchanger with two concentric tubes. Water flows down the inner tube and then up the annulus between the tubes. The external surface of the outer tube is heated by cylindrical radiant (resistive) heaters. The facility was designed with the controls and instrumentations to quantitatively characterize the flow and heat transfer.

The results of experiments in the facility showed that we could obtain steady input heat fluxes up to 50 $\mathrm{kW} / \mathrm{m}^{2}$ of heat-exchanger area. During operation the system would remain in a stable mode, with no flow instabilities or hot spots, under conditions from $100 \%$ liquid to superheated steam. We found that the central downcomer needed insulation to decrease the heat-transfer rates from the heated annular space. Our experiments showed that the long-tube heatexchanger concept was scientifically and technically feasible. More detailed information can be found in Lee et al (1978).

\section{Flowing Lava Heat-Flux Experi- ments}

The 1977 eruption along the east rift zone of Kilauea Volcano, Hawaii, provided us with an ideal field laboratory for the measurement of heat flux from flowing lava. The eruption produced a river of basaltic lava that flowed for several days. We could approach the very edge of this river to conduct experiments. A heat-transfer probe containing the heat-flux gages was inserted into an eddy in the river to measure the conduction-dominant heat-transfer rates from the molten lava into the cold probe. During a 5-min test, the primary heat-flux gage indicated transientdecaying conduction-dominant heat fluxes ranging from $200 \mathrm{~kW} / \mathrm{m}^{2}$ down to $50 \mathrm{~kW} / \mathrm{m}^{2}$. A secondary heat-flux gage verified that convective heat-flux rates, caused either by natural or forced convection in the 
eddy, were on the order of $10 \mathrm{~kW} / \mathrm{m}^{2}$ or less. Theoretical calculations of the expected conduction-dominant heat-transfer rates between the molten lava and the probe agree with the experimental results from the primary gage to within an error of $20 \%$ or less. For additional information, see Hardee (1979b).

\section{Molten Lava Heat-Flux Laboratory Experiments}

Following the described successful flowing lava experiment, we initiated a series of convective heattransfer experiments in the laboratory, using open and pressurized furnaces. Both steady-state convection probes and transient convection probes were used. In the steady-state probe, heat is removed at a measured rate across a known-value insulator in direct contact with the molten rock. In the transient probe, the transitory temperature response of a refractory metal in contact with the molten rock is used to determine the convective heat flux. Hardee and Dunn (1981) provide a more detailed description of these probes. Figure 14 (Hardee and Dunn, 1981) shows typical convective heat-flux data for molten, degassed basalt at liquidus and subliquidus temperatures. This data, taken with both steady-state and convection probes, compares well with two theoretical calculations. The data shows a definite change in slope at a temperature of $1212^{\circ} \mathrm{C}$ which is very close to the expected liquidus temperature of $1220^{\circ} \mathrm{C}$. This suggests that a change in convection occurs near the liquidus, probably caused by the change in rheology above and below this point.

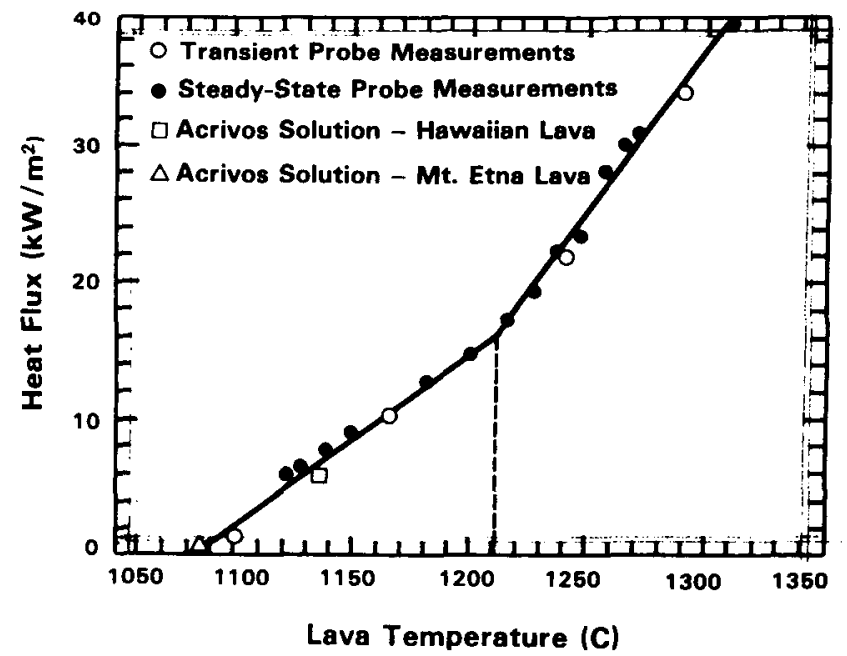

Figure 14. Convection Heat Flux Data From Laboratory Measurements in Basalt (after Hardee and Dunn, 1981).

\section{Lava Lake Extraction Experi- ments}

Laboratory material compatibility studies described in Chapter V and the Molten Lava/SingleTube Boiler Experiment described above has shown us that there are materials that will survive the environment, and techniques that will allow us to extract energy from molten rock. To confirm these results we have performed two series of energy-extraction experiments in the only natural molten-rock deposit available to us, Kilauea Iki lava lake. As stated earlier, the molten lava in the lake is a direct analog to a magma resource except for its volatile content and geostatic pressure. It is a suitable thermal analog. We regard it as a conservative analog because of its sharply decreased viscosity, since it is in its later stages of cooling.

We ran the first lava lake energy-extraction experiment during the 1978-79 lava lake drilling program described in Chapter III. The final series of experiments was performed during the 1981 lava lake experiment. We examined the extraction of energy using two techniques: one, using a completely sealed system (like the molten-lava laboratory experiment) in the hot rock at the upper margin of the melt zone; the other, using an "open" heat exchanger directly in the melt.

\section{Margin Zone Experiments}

We performed the initial energy-extraction experiment in the margin zone of the lava lake in 1979, using drillhole K.I. 79-4. This hole did not penetrate the melt, but was bottomed in the hot upper margin of the melt zone. Measured amounts of water were pumped down a center pipe in the cased drillhole to about 53-m depth. The steam was returned up the annulus between the center downcomer and the outer casing to a condensing calorimeter and weighed. Two runs of $45 \mathrm{~min}$ and $90 \mathrm{~min}$ duration were made. An average heat flux of 11 to $12 \mathrm{~kW} / \mathrm{m}^{2}$ was measured (Colp, 1979a).

The measured heat flux was higher than the calculated value using the expected conduction-only process. We believe that the increased heat flux measured was a result of porous convection in the hot rock induced by residual drilling water and steam outside the sealed casing. The results suggested the possibility of increasing heat transfer in magma chamber margins by the injection of a fluid for convection enhancement.

The final margin zone energy-extraction experiment was performed in the 1981 lava lake series. A closed, counterflow heat exchanger was placed in the 
lava lake above the magma zone. This was accomplished by casing a cored hole to a depth of $180 \mathrm{ft}$ with AW (diameter $=2.25 \mathrm{in}$.) casing that was closed and sealed on the downhole end. A downcomer of 3/4-in. stainless-steel tubing was inserted through an aboveground casing seal, then down inside the casing to a depth of $179 \mathrm{ft}$. Water was pumped at a constant rate through the downcomer, up the casing annulus, then routed through above-ground piping on the surface where temperature and flow-rate measurements were taken. Three downhole temperatures were also measured: bottom of the casing, downcomer at a depth of $101 \mathrm{ft}$, and downcomer at a depth of $160 \mathrm{ft}$. The heat exchanger was in contact with two distinct layers of the lava lake. The first, called the upper crust, extended from 0 to $150 \mathrm{ft}$. This region is highly fractured, permeable, and almost isothermal at $100^{\circ} \mathrm{C}$. The second, called the transition zone, is more dense than the upper crust, has low permeability, and temperatures that rise from $100^{\circ} \mathrm{C}$ to $\sim 1100^{\circ} \mathrm{C}$ at the melt zone.

After $2 \mathrm{~h}$ of operation, rates of heat transfer to the cooling water were about $10 \mathrm{~kW} / \mathrm{m}^{2}$ in the hot transition zone and $4.6 \mathrm{~kW} / \mathrm{m}^{2}$ in the upper crust. This latter rate is a factor of 4.2 above the predicted conduction heat-transfer rate for the upper crust. The enhancement can be explained by a convective transport of heat in the upper crust caused by natural movement of steam in the formation. A similar experiment conducted during the 1979 lava lake experiments reached the same conclusion concerning enhanced heat-transfer rates in the upper crust. However, the 1979 experiment produced heat-transfer rates in the upper crust that were about six times the conduction rates. This difference could be explained by the larger amount of drilling water (and/or rainfall) present in the formation at the time of the 1979 experiment. Steam was venting from the surface of the lake around the 1979 experimental drillhole; this was not the case during the 1981 experiment.

This method of energy extraction could be used in the hot solid margin zones surrounding magma bodies at depth. By taking advantage of existing permeable convection or by stimulating convection with fluidinjection, energy-extraction rates can be greater than rates obtained with pure conduction.

\section{Melt Zone Experiments}

An improvement on the amount of energy extracted from a borehole into a magma resource has a very beneficial effect on the efficiency of the magmaenergy concept. Increasing the size of the heatexchanger surface area in contact with the magma can create this improvement. One method for increasing the heat-exchanger surface area consists of injecting water directly into the magma and forming a large fractured crust of permeable solidified rock adjacent to the borehole. In this "open heat exchanger" concept, water is circulated through this hot fractured zone where the water is converted to steam and withdrawn. 'Two methods of steam generation can be used: continuously, by injecting water at one depth and withdrawing steam at a lesser depth, and cyclically, by injecting water for a time, sealing off the system, and then venting the higher pressure steam. We demonstrated the open heat-exchanger concept using both steam generation methods in the final lava lake energy-extraction experiments in 1981.

A hole drilled to a depth of $68 \mathrm{~m}$ extended approximately $10 \mathrm{~m}$ into the melt zone. Casing was set from the surface to the full depth. We then reduced the cooling water flow down the casing, allowing the melt to flow and seal around the end of the casing. The hole was then extended to a depth of $74 \mathrm{~m}$ by drilling through the casing an additional $6 \mathrm{~m}$. The final geometry of the experiment was a sealed (cased) conduit from the surface of the lava lake to an open (uncased) 6 -m experimental section in the molten zone. A central downcomer instrumented with thermocouples was inserted to near the bottom. Pressure sensors were installed in the piping system on the lake surface (see Figure 15).

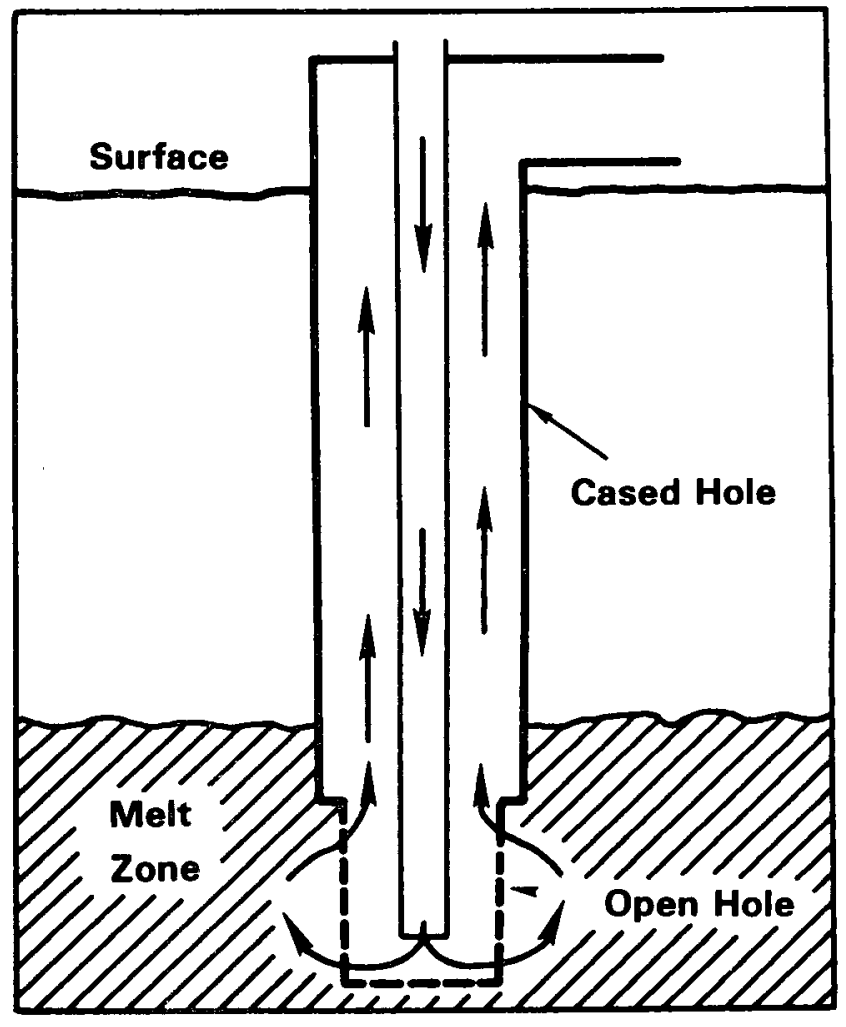

Figure 15. Schematic Drawing of 1981 Lava Lake Open Heat-Exchanger Experiment (after Dunn, 1981). 
Pressurized water was injected through the downcomer into the open experimental section under steady and intermittent conditions for a week's duration. The continual cooling of the experimental section by the pressurized water caused solidification and thermal fracturing of the molten region surrounding the borehole. Thermal stress analysis of this cooling configuration shows that both radial and horizontal fractures should occur, resulting in a highly permeable, rubbled bed of fractured rock. A finite thickness of near molten, plastic rock surrounds this cooler, rubbled zone, acting as a seal to prevent fluid loss. All of the water ( $95 \%$ to $100 \%$ ) injected into this rubbled cavity in the molten zone during the experiments was recovered during the steam injection phase, demonstrating that a closed, sealed cavity had indeed been produced in the melt. Steam generated by the contact of water with the very hot molten zone was either exhausted to the atmosphere or directed to a condensing calorimeter to measure the energy-extraction rates. By controlling the water injection, we could establish either steady production of steam or a periodic geysering action. Energy-extraction rates as high as $950 \mathrm{~kW} / \mathrm{m}^{2}$ were measured during transient operation. During steady water-injection operation, an energy-extraction rate of $180 \mathrm{~kW} / \mathrm{m}^{2}$ was measured. The energy-extraction rates are based on the surface area of the original borehole into the molten zone. For further information on this experiment, see Hardee et al (1981).

During the first $48 \mathrm{~h}$ of experiment operation, energy-extraction measurements showed that heat flux based on original borehole surface area increased with time (Figure 16). The transient behavior was opposite that expected for conductive heat transfer in a solid, indicating that the rubblized region surrounding the original borehole grew with time, increasing the heat-transfer area for energy extraction. This effective area has been calculated and shown as a function of time in Figure 17. The factor of 10 increase in effective heat-transfer area is significant and was reached after only 2 days' operation.

These results show the value of the open heatexchanger concept to extract energy at high rates even in settings where convective transport is absent and heat transfer is limited to pure conduction.

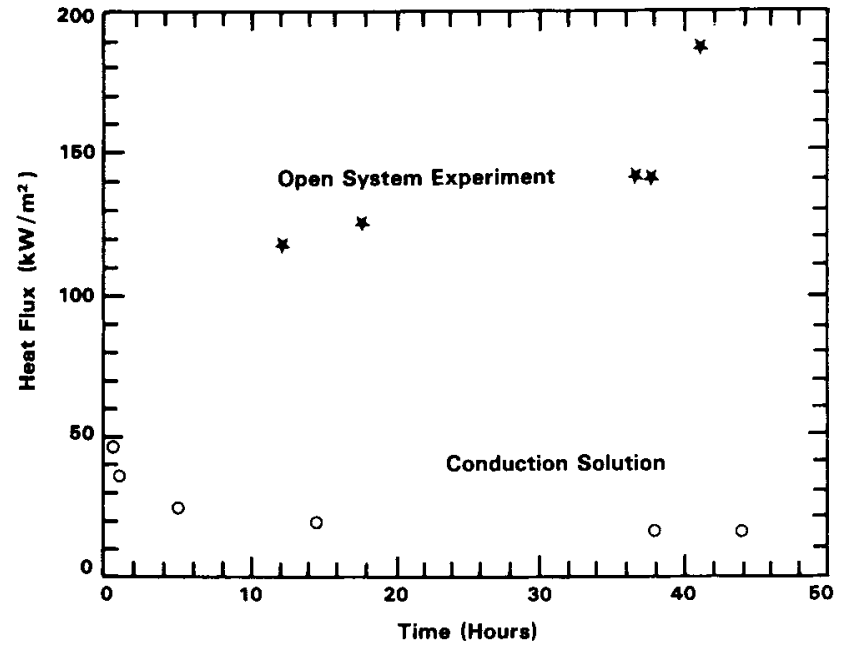

Figure 16. 1981 Lava Lake Open Heat-Exchanger Experiment Results Showing Heat-Flux Measurements Based on Original Borehole Area (after Dunn, 1981).

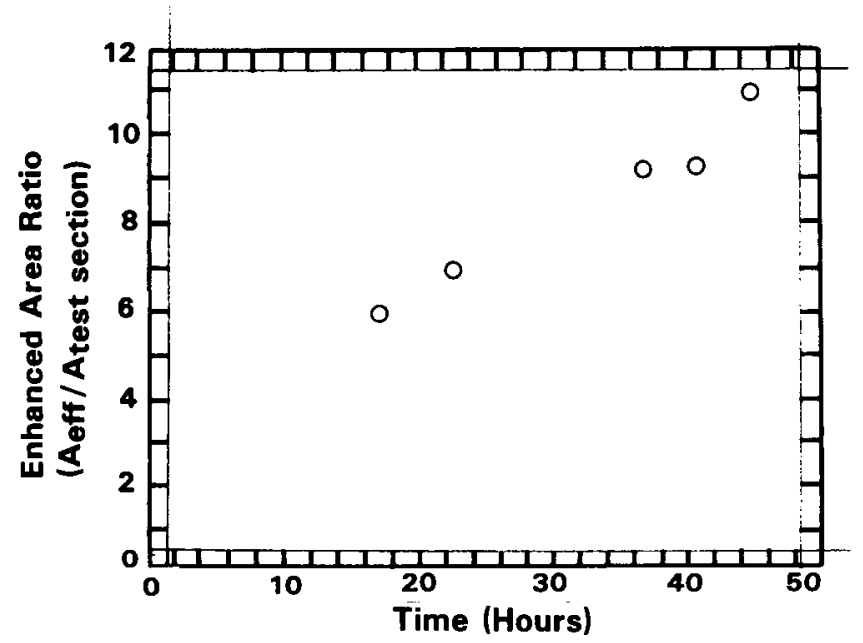

Figure 17. 1981 Lava Lake Open Heat-Exchanger Experiment Results Showing the Growth in Energy Exchange Area with Time (after Dunn, 1981). 


\section{Magma In-Situ Convection Lab- oratory Experiments}

The Magma Simulation Facility described in Chapter IV was used to measure heat-transfer rates in a magma under pressure and temperature conditions simulating those of a real magma system within 5 to 10 $\mathrm{km}$ of the surface. The heat-transfer experiments are designed to quantify the effect of dissolved $\mathrm{H}_{2} \mathrm{O}$ on convective heat transfer in a magma. Initial data obtained at $200 \mathrm{MPa}$ for degassed Cuberio basalt (a local New Mexico alkali basalt) show significant convective behavior when mean temperatures exceeded $1225^{\circ} \mathrm{C}$.

A unique crucible design was used to obtain data for a large $(0.5 \mathrm{~L})$ basaltic sample to which $3 \mathrm{w} / \mathrm{o} \mathrm{H}_{2} \mathrm{O}$ was added to achieve $65 \%$ water saturation at the liquidus. The Magma Simulation Facility was operated continuously under computer control for a 5-day period at $200 \mathrm{MPa}$. Several stable temperature conditions near the liquidus were established in the sample during this 5-day period. Convective heat-transfer rates in the "wet" magma were as much as $35 \%$ greater than corresponding convective rates measured in the "dry" sample (Luth and Hardee, 1982).

A two-dimensional axisymmetric finite-element computer code has been used to numerically model the heat-transfer experiment. Temperaturedependent transport properties of the magma are included. Viscosity was calculated, using the procedure described by Shaw for estimating temperaturedependent visosity of a magmatic silicate liquid from its chemical analysis. Computed heat-transfer results are in excellent agreement with the experimental results obtained (ibid).

\section{Fuel Generation}

In addition to the obvious exploitation of magmathermal energy for electric-power generation, alternative applications of magma energy are also under investigation. The alternatives include an interest in use of magma resources for production and refinement of fuels (Northrup et al, 1978). Indeed, the most serious aspect of the energy problem in the near-term may be the depletion of fuel resources.

Northrup et al (1978) outline two methods for generating gaseous fuels in high-temperature magmatic environments: (1) $\mathrm{H}_{2}$ generation by the interaction of water with ferrous iron-oxide in magma or very hot rock, and (2) $\mathrm{H}_{2}, \mathrm{CH}_{4}$, and $\mathrm{CO}$ generation by conversion of water-biomass mixtures at high temperatures in magmatic environments. The first method has the advantage of being more than a fuelreinfinement process, but it also has several potential disadvantages (Gerlach, 1982).

The second method proposed by Northrup et al (1978) is essentially a fuel conversion or refinement process. Raw biomass is itself a fuel, but it can be hydrogenated and converted to more desirable higher quality gaseous fuels at high temperatures in the presence of water.

There are ample options for generating gaseous fuels from water-biomass conversion with magmathermal energy. A wide range of magma types and pluton styles believed to occur within the upper $10 \mathrm{~km}$ of the crust provide suitable sources of thermal energy for water-biomass conversion throughout magma lifetimes of 1500 to 600000 yrs. Fuels can be generated within a magma body, within the hot subsolidus margins of a magma body, or within surface reaction vessels heated by thermal energy derived from a magma body. The surface reactor scheme is particularly attractive for dealing with the problems of biomassderived sulfur and ash accumulation during fuel generation.

The composition, concentration, and energy content of the fuel gases generated from a particular water-biomass mixture does not change appreciably with the type, age, depth, or temperature of the magma body. For any upper crustal magma body, the concentration of generated fuel and its energy content is almost entirely a function of the proportion of biomass in the starting mixture. $\mathrm{CH}_{4}$ is the main gas that can be generated in important quantities by magma-thermal energy under most circumstances. The possibilities for significant $\mathrm{H}_{2}$ generation are restricted either to heat exchangers operating at high temperatures $\left(>800^{\circ} \mathrm{C}\right)$ in the tops of very shallow basaltic magma bodies (e.g., midocean ridge basalts) or to surface reaction vessels operating at temperatures in excess of $600^{\circ} \mathrm{C}$. Under either of these conditions, $\mathrm{H}_{2}$ production would be achieved at the cost of a reduction in the rates of both fuel generation and heat extraction by associated steam production.

The rate at which gaseous fuels can be generated from water-biomass mixtures is strongly dependent on the type of magma involved. Fuel generation rates for basaltic magmas are at least 2 to 3 times those for andesitic magmas and 5 to 6 times those for rhyolitic magmas for similar biomass concentration levels and generating temperatures. For any given magma, the 
highest fuel generation rates will be achieved at the lowest possible operating temperature that does not cause graphite deposition from the water-biomass mixture being employed.

The problem of graphite deposition would, therefore, have to be solved for each particular environment of interest, but a few generalizations can be made from a thermochemical point of view for fuel generation in heat exchangers operating in upper crustal magma bodies:

- At $300^{\circ} \mathrm{C}$, less than $10 \%$ biomass can be used

- At $400^{\circ} \mathrm{C}, 10 \%$ to $20 \%$ biomass can be used, depending on depth

- At $500^{\circ} \mathrm{C}, 20 \%$ to $30 \%$ biomass can be used, depending on depth

- At temperatures in excess of $600^{\circ} \mathrm{C}, 30 \%$ to $40 \%$ biomass can be used

Inasmuch as fuel generation rates would be optimized at lower temperatures $\left(400^{\circ}\right.$ to $\left.500^{\circ} \mathrm{C}\right), 20 \%$ biomass is probably a realistic upper limit for biomass concentrations in the starting mixtures for downhole production. This concentration level may also prove to be an upper limit for other reasons not considered in this study (economic factors, technical factors related'to preparation of starting mixtures, etc). The surface reactor circumvents the problem of graphite deposition down to $300^{\circ} \mathrm{C}$ even for biomass concentrations up to $40 \%$.

The energy content of the biomass-derived fuels is considerably greater by a factor of 6 to 12 than that consumed in the generation and refinement process for all conditions examined, especially at lower operating temperatures. The energy costs of biomass production, harvest, collection, transport, and preparation for refinement must ultimately be included in this accounting. However, the very large factors involved would seem to leave a comfortable margin for these costs. For more information, see Gerlach (1982) and Gerlach and Hardee (in publication).

\section{Summary}

Calculational and laboratory studies have shown the following:

- Attractive energy-extraction rates $(>10 \mathrm{~kW} /$ $\mathrm{m}^{2}$ ) can be achieved with convective heat transfer in basaltic and andesitic magmas using open or closed heat exchangers, while rhyolitic magmas require the use of open heat-exchanger systems.
- The temperature differential between an operating closed heat exchanger $\left(300^{\circ}\right.$ to $\left.600^{\circ} \mathrm{C}\right)$ and the magma $\left(900^{\circ}\right.$ to $\left.1400^{\circ} \mathrm{C}\right)$ induces convection in the magma when the heat exchanger is emplaced. At low magma convection rates, a large diameter crust forms on the heat exchanger. This geometrical enhancement in surface area for convection compensates for the low convection rates, making a closed heat exchanger a viable energy-extraction concept. This area enhancement results in attractive heat-transfer rates even in partially molten (subliquidus) basaltic and andesitic bodies.

- The open heat-exchanger concept produces energy-extraction rates 10 to 100 times greater than rates produced by closed heat-exchanger systems.

- Long (>100-m) tube vertical heat exchangers work effectively; gravity head and other effects can be controlled.

- High-pressure experiments confirm that pressure alone has little effect on molten-rock convection rates; however, the presence of normal $(\sim 3 \mathrm{w} / \mathrm{o})$ amounts of water result in a $35 \%$ improvement in convective heat transport.

- Two methods can be used to generate gaseous fuels in high-temperature magmatic environments:

- $\mathrm{H}_{2}$ generation by the interaction of water with ferrous iron in magma or very hot rock.

- $\mathrm{H}_{2}, \mathrm{CH}_{4}$, and $\mathrm{CO}$ generation by the conversion of water-biomass mixtures at magmatic temperatures.

- The composition, concentration, and energy content of the fuel gases generated from a particular water-biomass mixture does not change appreciably with the type, age, depth, or temperature of the magma body. The concentration of generated fuel and its energy content is almost entirely a function of the proportions of biomass in the starting mixture.

- The rate at which gaseous fuels can be generated from water-biomass mixtures is strongly dependent on the type of magma involved: Fuel generation rates for basaltic magmas are at least 2 to 3 times those for andesitic magmas and 5 to 6 times those for rhyolitic magmas for similar biomass concentration levels and generating temperatures. 
- The energy content of the biomass-derived fuels is 6 to 12 times greater than the energy consumed in its generation for all conditions examined. results:

Field experiments have produced the following

- Margin-zone heat exchangers offer a way to extract energy from hot, solid margins that exist around magma bodies or that may exist in dispersed magma bodies where the magma is emplaced in a plexus of dikes and sills.

- An open heat exchanger can be formed in a viscous $(<40 \%$ melt) molten-rock body. The enclosed cavity expands in size until thermal balance is achieved and the cavity is continuously sealed by a plastic, glassy exterior to contain the heat-transfer fluid.
- An open heat-exchanger experiment showed an enhancement in effective heat-transfer area 10 times that of the original borehole area, demonstrating that the open heat-exchanger concept allows the extraction of energy at high rates even in magma bodies where convective transport is absent and heat transfer is limited to pure conduction.

- We have demonstrated through calculations, laboratory studies, and field experiments that there are no insurmountable theoretical or physical barriers to prevent the extraction of energy at attractive rates from any type of molten or partially molten magma body or the margins enclosing it; therefore, we conclude that energy extraction is scientifically feasible. 


\section{Conclusions About Scientific Feasibility}

The objective of the Magma Energy Research Project was to assess the scientific feasibility* of extracting energy directly from deeply buried magma sources. During the $7 \mathrm{yr}$ that this project was funded by the Department of Energy and its predecessors, we studied key aspects of the magma concept; locating, tapping, characterizing, extracting energy, and assessing the compatibility of engineering materials. As a result of these studies, we have demonstrated that it is scientifically feasible to extract energy from magma. Two different scientific review panels have agreed.

\section{Source Location and Definition}

The existence of magma resources in the earth's outer crust is shown directly by geological evidence and indirectly by geophysical evidence. The direct geological evidence of the past existence of magma bodies consists of exhumed fossilized magma bodies, collapsed volcano calderas, and recent-dated lava flows. Evidence of the current existence of magma bodies consists of long-lived geothermal systems and active volcanoes. The indirect geophysical evidence of current magma bodies consists of the delays observed in receiving teleseismic $P$-wave, the shadowing of shear waves during reception, the results of cyclic seismic reflection studies, tilt measurements, and magnetic and gravity anomalies.

We have accepted the US Geological Survey's estimate of the size of the molten and near-molten rock resource (50000 to 500000 quads) within the top $10 \mathrm{~km}$ of the earth's surface.

Our computational and laboratory studies show that any physical configuration of the magma resource is practical for the extraction of thermal energy at attractive $\left(>10 \mathrm{~kW} / \mathrm{m}^{2}\right)$ rates. Basalt or andesite pools are suitable for the use of closed heat exchangers. Basalt, andesite, or rhyolite pools or matrices of dikes and sills are suitable for the use of the open heatexchanger concept. Any type of near-molten pluton, even though at subsolidus temperature, is suitable for the use of a margin zone heat exchanger.

\footnotetext{
* We define "scientific feasibility" as the demonstration, by means of theoretical calculations and supporting laboratory and field measurements, that there are no known insurmountable theoretical or physical barriers that invalidate a concept or process.
}

Six years of geophysical experimentation over the known molten lava lens in Kilauea Iki lava lake (a suitable magma analog) has shown that current geophysical sensing systems can be used for measurements in such an environment. However, those results have confirmed that the magma source environment is very complex, making the unambiguous interpretation of geophysical sensing results very difficult. Also, all possible geophysical techniques must be used in a magma exploration program because no single technique will provide adequate data.

Our recent interviews with qualified experts in industry, academic, and Federal agencies showed that they believe shallow magma bodies exist and that existing geophysical sensing systems (hardware and software) are adequate to locate and define these bodies.

Based on the above evidence, we have concluded that the location and definition of shallow magma bodies is scientifically feasible; that is, no insurmountable barriers exist to prevent the performance of this task.

\section{Source Tapping}

Numerous holes have been drilled in the earth's crust to depths of 7 to $10 \mathrm{~km}$, with bottom hole temperatures ranging up to $220^{\circ} \mathrm{C}$. Commercial manufacturers can construct drilling rigs capable of drilling to $15 \mathrm{~km}$. Many geothermal wells have been drilled to depths of 3 to $5 \mathrm{~km}$, with bottom hole temperatures ranging over $400^{\circ} \mathrm{C}$. The Icelanders have suecessfully drilled into molten rock with bottom hole temperatures of $>900^{\circ} \mathrm{C}$. We have drilled over $100 \mathrm{~m}$ of molten rock $\left(\mathrm{T}>1020^{\circ} \mathrm{C}\right)$.

Our laboratory studies have demonstrated that typical magma roof-rocks at in situ (10-km depth) temperatures and pressures exhibit brittle failure up to melt conditions and should be drillable with current bit types. Further, boreholes in magma roof-rocks at in situ conditions can be kept open and stable by proper cooling and filling.

Our 5 yr of drilling experience in Kilauea Iki lava lake (a suitable magma analog) taught us that

- Drill bits optimized for high-velocity coolant flow are required to successfully drill through molten rock at temperatures of $1020^{\circ} \mathrm{C}$ to $1170^{\circ} \mathrm{C}$ 
- Boreholes in molten rock can be kept open and stable for extended periods of time (on the order of days) with no problems

- On-site petrologic analysis of freshly drilled core samples is necessary so that bottom-hole conditions are known as drilling proceeds

The above knowledge has enabled us to conclude that it is scientifically feasible to drill into magma sources.

\section{Magma Characterization}

Modeling studies have predicted the gas compositions of in situ magmas from data resulting from the analysis of surface emissions of volcanic gases. These modeled compositions are used in magma property experiments and magma/material compatibility tests.

Petrologic studies provide insights on the cooling history of magma body analogs that are useful in predicting magma body lifetimes.

Experiments run in our unique Magma Simulation Facility at in situ conditions show that an increase of $3 \mathrm{w} / \mathrm{o}$ in the water content of molten basalt results in a $35 \%$ greater convective heat-transfer rate.

The results of our studies lead us to conclude that current property data is adequate for engineering analyses and that facilities exist for obtaining more data as needed. It is scientifically feasible to achieve the degree of characterization of magma required.

\section{Magma/Material Compatibility}

Laboratory corrosion studies show that (1) currently available engineering metals are compatible with molten magma under expected normal operating temperatures $\left(300^{\circ}\right.$ to $\left.600^{\circ} \mathrm{C}\right)$ for plant lifetimes $(30$ yr) and (2) metal alloys can be selected that will be compatible with molten magma under emergency (loss of coolant) temperatures $\left(700^{\circ}\right.$ to $\left.1100^{\circ} \mathrm{C}\right)$ for their expected duration (a few hundred hours).

Based on these results, the conclusion is reached that it is scientifically feasible to expect that engineering materials are compatible with the expected magma environment.

\section{Energy Extraction}

Calculational and laboratory studies show that attractive energy extraction rates can be achieved with convective heat transfer in basaltic and andesitic magmas using open or closed heat exchangers and in rhyolitic magmas using open heat exchangers. Long tube vertical heat exchangers have been shown to work effectively. High-pressure experiments indicate that molten-rock convection rates show improvements of $35 \%$ when $3 \mathrm{w} / \mathrm{o}$ water is present. Hydrogen fuel will be generated by the interaction of water with ferrous iron in magma or very hot rock; $\mathrm{H}_{2}, \mathrm{CH}_{4}$, and $\mathrm{CO}$ will be generated by water-biomass-mixture conversion at magmatic temperatures.

Field experiments in an analog magma source show that margin-zone heat exchangers can extract energy from hot, solid margins around magma bodies and that open heat exchangers form in viscous $(<40 \%$ liquid) molten-rock bodies with sealed, permeable cavities of rubbled rock that continuously expand in size.

Our conclusion is that the extraction of energy from magma in all petrologic compositions and physical configurations is scientifically feasible and, in some cases, has been demonstrated in a reasonable magma analog. 


\section{Bibliography}

Aki, K., B. Chouet, M. Fehler, G. Zandt, R. Koyanagi, and J. Colp, "Seismic Properties of a Shallow Magma Reservoir in Kilauea Iki by Active and Passive Experiments," $J$ Geophy Res, V 83, n B5 (May 10, 1978).

Anderson, L., Private communication of preliminary VLF data to John Colp (1976).

Anon, “Deep Arbuckle,” DRILLING-DCW, pp 22-25 (July 1974).

Anon, "Soviets Drill World's Deepest Hole to Almost 35000 Feet," Oil and Gas Journal, p 60 (March 1981).

Bostick, F. X., H. W. Smith, and J. E. Boehl, Audio Magnetotelluric Measurements on Kilauea Iki Lava Lake, Report to Sandia Laboratories (1977)

Colp, J. L., FY 79 Lava Lake Drilling Program - Geoscience Studies, Plans and Results, SAND79-1361 (Albuquerque, NM: Sandia Laboratories, 1979)

Colp, J. L., Magma Energy Research Project FY79 Annual Progress Report, SAND79-2205 (Albuquerque, NM: Sandia Laboratories, 1979).

Colp, J. L., FY80 Annual Progress Report - Magma Energy Research Project, SAND81-0100 (Albuquerque, NM: Sandia National Laboratories, 1982) p 104.

Colp, J. L. and A. S. Furumoto, "The Utilization of Volcano Energy," Proceedings of the U.S./Japan Conference at Hilo, HI on February 4-8, 1974 (Albuquerque, NM: Sandia Laboratories, 1974) p 680.

Colp, J. L., R. W. Decker, J. F. Hermance, D. L. Peck, and P. L. Ward, Magma Workshop Assessments and Recommendations, SAND75-0306 (Albuquerque, NM: Sandia Laboratories, July 1975).

Colp, J. L. and G. E. Brandvold, "The Sandia Magma Energy Research Project," Proceedings, Second United Nations Symposium on the Development and Use of Geothermal Resources, San Francisco, CA, May 1975, (1976), p 1599-1607.

Colp, J. L., M. J. Davis, E. J. Graeber, and H. C. Hardee, Magma Energy Research Project - Project Summary, July 1, 1974 - June 30, 1975, SAND75-0451 (Albuquerque, NM: Sandia Laboratories, 1976).

Colp, J. L. and R. Okamura, "Drilling Into Molten Rock at Kilauea Iki," Transactions, Geothermal Resources Council, Vol 2, July 1978, pp 105-108.

Colp, J. L. and R. K. Traeger, Magma Energy Research Project - Status Report as of October 1, 1978, SAND78-2288 (Albuquerque, NM: Sandia Laboratories, December 1979), p 159.

Davis, M. J. and D. J. Mottern, Material Selection and Processing for the Molten-Lava/Single-Tube Boiler Experiment, SAND75-0055 (Albuquerque, NM: Sandia Laboratories, 1975).

Douglass, D. L. and J. T. Healey, The Corrosion of Some Pure Metals in Basaltic Lava and Simulated Magmatic Gas at $1150^{\circ} \mathrm{C}$, SAND79-1981 (Albuquerque, NM: Sandia Laboratories, 1979).
Douglass, D. L. and J. T. Healey, "The Corrosion of Some Pure Metals in Basaltic Lava and Simulated Magmatic Gas at $1150^{\circ} \mathrm{C}, "$ Oxid Metals, 15, 1981, p 21.

Douglass, D. L. and J. T. Healey, "The Corrosion of Ferritic and Austenitic Stainless Steels in Basaltic Lava and Simulated Magmatic Gases," NACE International Conference on High-Temperature Corrosion, San Diego, CA, March 2-6, 1981, to be published.

Dunn, J. C., personal communication to J. L. Colp (1981).

Ehrlich, S. A. and D. L. Douglass, The Effect of Molybdenum Plus Chromium on the Corrosion of Iron-, Nickel-, and Cobalt-Base Alloys in Basaltic Lava and Simulated Magmatic Gas at $1150^{\circ} \mathrm{C}$, SAND 82-7055 (Albuquerque, NM: Sandia National Laboratories, 1982) p 75.

Fewell, M. E., H. C. Hardee, and P. C. Montoya, Design of a Molten-Lava/Single-Tube Boiler Experiment, SAND75-0080 (Albuquerque, NM: Sandia Laboratories, 1975).

Flanigan, V. J. and C. J. Zablocki, "Mapping the Lateral Boundaries of a Cooling Basaltic Lava Lake, Kilauea Iki, Hawaii," USGS Open-File Report 77-94, 1977, p 21.

Friedman, M., J. Handin, N. G. Higgs, J. R. Lantz, and S. J. Bauer, Strength and Ductility of Room-Dry and WaterSaturated Igneous Rocks at Low Pressures and Temperatures to Partial Melting, SAND80-7159 (Albuquerque, NM: Sandia National Laboratories, November 1980).

Gerlach, T. M., "Evaluation and Restoration of the 1970 Volcanic Gas Analyses From Mount Etna, Sicily," Jr Volc and Geoth Res, 6 (1979), p.165-178.

Gerlach, T. M., "Evaluation of Volcanic Gas Analyses from Kilauea Volcano," Jr Volc and Geoth Res, 7, (1980A) 295-317.

Gerlach, T. M., "Investigation of Volcanic Gas Analyses and Magma Outgassing From Erta Ale Lava Lake, Afar, Ethiopia," Jr Volc and Geoth Res, 7, (1980B) p 415-441.

Gerlach, T. M., "Chemical Characteristics of the Volcanic Gases From Nyiragongo Lava Lake and the Generation of $\mathrm{CH}_{4}$-Rich Fluid Inclusions in Alkaline Rocks," Jr Volc and Geoth Res, (1980C) in press.

Gerlach, T. M., "Evaluation of Volcanic Gas Analyses from Surtesy Volcano," Jr Volc and Geoth Res, (1980D) in press.

Gerlach, T. M., "Restoration of New Volcanic Gas Analyses From Basalts of the Afar Region: Further Evidence of CO2-Degassing Trends," Jr Volc and Geoth Res, (1981A) in press.

Gerlach, T. M., Analysis of Magma-Thermal Conversion of Biomass to Gaseous Fuel, SAND82-0031 (Albuquerque, NM: Sandia National Laboratories, 1982) p 55.

Gerlach, T. M. and H. C. Hardee, "Gaseous Fuel Generation by Magma-Thermal Conversion of Biomass," Journ Energy, 1983 (in publication). 
Hardee, H. C., Heat Extraction From a Magma Reservoir, SAND74-0328 (Albuquerque, NM: Sandia Laboratories, 1974).

Hardee, H. C., Molten-Lava/Single-Tube Boiler Experiment, SAND75-0069 (Albuquerque, NM: Sandia Laboratories, 1975).

Hardee, H. C., "Heat Extraction From Magma Bodies," Proceedings, Hawaii Symposium on Intraplate Volcanism, Hilo, HI, 1979a.

Hardee, H. C., "Heat-Transfer Measurements in the 1977 Kilauea Lava Flow, Hawaii,” JGR, V 84, n B13 (1979b) pp 7485-7493.

Hardee, H. C., "Solidification in Kilauea Iki Lava Lake," $J$ Volc Geoth Res 7 (1980) pp 211-223.

Hardee, H. C., "Convective Heat Extraction From Molten Magma," J Volc Geoth Res, 10 (1981) pp 175-183.

Hardee, H. C. and M. E. Fewell, Molten Lava/Single-Tube Boiler Experiment, SAND75-0069 (Albuquerque, NM: Sandia Laboratories, 1975).

Hardee, H. C. and D. W. Larson, "The Extraction of Heat From Magmas Based on Heat-Transfer Mechanisms," $J$ Volc Geoth Res, 2 (1977) pp 113-144.

Hardee, H. C. and J. C. Dunn, "Convective Heat Transfer in Magmas Near the Liquidus," J Volc Geoth Res, 10 (1981) pp 195-207.

Hardee, H. C., J. C. Dunn, R. G. Hills, and R. W. Ward, "Probing the Melt Zone of Kilauea Iki Lava Lake, Kilauea Volcano Hawaii," Geop Res Letters, V 8, n 12 (December 1981) p 1211-1214.

Hardee, H. C., J. C. Dunn, and J. L. Colp, Magma Source Location Survey, SAND82-0219 (Albuquerque, NM: Sandia National Laboratories, March 1982) p 63.

Hermance, J. F., D. W. Forsyth, and J. L. Colp, Geophysical Sensing Experiments on Kilauea Iki Lava Lake, SAND78-0828 (Albuquerque, NM: Sandia Laboratories, November 1979).

Hermance, J. F. and J. L. Colp, "Kilauea Iki Lava Lake: Geophysical Constraints on its Present (1980) Physical State," J Volc \& Geoth Res, 13, (1982) p 31-61.

Jonsson, V. K. and M. Matthiasson, "Hraunkaeling a Heimaey-Verklegar Framkvaemoir, Timant VF1," Bull Iceland Eng Soc) V 59 (1974) p 70-83.

Larson, D. W., J. C. Dunn, and H. C. Hardee, "Magma Energy Extraction Status," Abs. EOS, V 62, n 45 (1981) p 1058.

Lee, D. O., W. D. Sundberg, P. C. Montoya, R. W. Johnson, and R. L. Weatherbee, Long Tube Heat Exchanger The Facility and Some Preliminary Tests on the Down Center/Up Annulus Flow Configuration, SAND78-0823 (Albuquerque, NM: Sandia National Laboratories, 1978).

LeGuern, F., T. M. Gerlach, and A. Nohl, "Field Gas Chromatograph Analyses of Gases From a Glowing Dome at Merap. Volcano, Indonesia, 1977, 1978, 1979," $J$ Volc Geoth Res, in publication (1982).

Luth, W. C., personal communication to J. L. Colp (1981).
Luth, W. C. and H. C. Hardee, Sandia/BES Geosciences Report-Second Quarter, Report to DOE/BES/Geosciences Office, 1982.

Moore, J. G., H. S. Fleming, and J. D. Phillips, "Preliminary Model for Extrusion and Rifting at the Axis of the MidAtlantic Ridge, $36^{\circ} 48^{\prime}{ }^{\prime \prime}$ Geology, V 2, n 9 (1974) pp 437-440.

Neel, R. R., R. P. Striker, and R. M. Curlee, FY79 Lava Lake Drilling Program - Results of Drilling Experiments, SAND79-1360 (Albuquerque, NM: Sandia Laboratories, November 1979).

Northrup, C.J.M., T. M. Gerlach, P. J. Modreski, and J. K. Galt, "Magma: A Potential Source of Fuels," International J. Hyd. Energy, 3 (1978) pp 1-10.

Sallach, R. A., Magma/Metal Compatibility Studies - Compatibility of Metals in Molten Degassed Tholeiitic Basalt, SAND75-0094 (Albuquerque, NM: Sandia Laboratories, 1975).

Smith, B. D., C. J. Zablocki, F. C. Frischknect, and V. J. Flanigan, "Summary of Results From Electromagnetic and Galvanic Soundings on Kilauea Iki Lava Lake," USGS Open File Report 77-59 (1977) p 27.

Smith, B. D., C. J. Zablocki, F. C. Frischknect, and D. B. Jackson, "Results From Electrical Studies of Kilauea Iki Lava Lake," Abs., Hilo Geothermal Conference, 1978.

Smith, R. L., and H. R. Shaw, "Igneous-Related Geothermal Systems" in U.S. Geological Survey Circular 726, Assessment of Geothermal Resources of the United States 1975 (1975) p 58-83.

Smith, R. L., and H. R. Shaw, "Igneous-Related Geothermal Systems," in U.S. Geological Survey Circular 790, Assessment of Geothermal Resources of the United States 1978 (1979) p 12-17.

Stauber, D. A., Progress Report on the Kilauea Iki Seismic Experiments of March 1980, Report to Sandia National Laboratories, Albuquerque, NM, 1980.

Traeger, R. K., S. G. Varnado, A. F. Veneruso, V. L. Behr, and A. Ortega, Drilling, Instrumentation, and Sampling Considerations for Geoscience Studies of MagmaHydrothermal Regimes, SAND81-0800 (Albuquerque, NM: Sandia National Laboratories, 1981) p 54.

Varnado, S. G. and J. L. Colp, Report of the Workshop on Magma/Hydrothermal Drilling and Instrumentation SAND78-1365C (Albuquerque, NM: Sandia Laboratories, 1978).

Wemple, R. P., W. F. Hammetter, and C. J. Greenholt, Development of High Temperature Viscosity Measurement Technique, SAND80-0641 (Albuquerque, NM: Sandia National Laboratories, 1980) p 27.

Wemple, R. P. Magma Simulation Facility Design Considerations, Capabilities, and Operational Considerations SAND80-2651 (Albuquerque, NM: Sandia National Laboratories, 1981) p 31.

Zablocki, C., "Some Electrical and Magnetic Studies on Kilauea Iki Lava Lake, Hawaii," USGS Open File Report 76-304, 1976, p 19. 


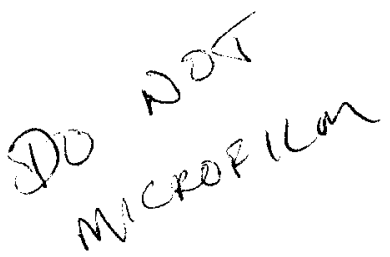

DISTRIBUTION:

DOE/TIC-4500-R70 UC-66 (236)

Argonne National Laboratory

Colorado School of Mines

(3)

9700 South Cass Ave

Argonne, IL 60439

Attn: M. Blander, Bldg 205

Golden, CO 80401

Attn: G. Keller

J. Applegate

T. Grose

F. J. Benson

817 N. Rosemary Dr.

Bryan, TX 77801

Sveinbjorn Bjornsson

Science Institute

University of Iceland

Bunhaga 3

107 Reykjavik, ICELAND

Brown University

Dept of Geological Sciences

Providence, RI 02912

Attn: J. F. Hermance

Chevron Oil Field Research Co.

PO Box 446

LaHabra, CA 90631

Attn: J. O'Brient

J. C. Martin

L. M. Cathles

Chevron Research Co.

576 Standard Ave

Richmond, CA 94802

Attn: H. F. Harnsberger

Chevron Resources Co.

PO Box 4001

Golden, CO 80401

Attn: C. M. Swift

Chevron Resources Co.

PO Box 3722

San Francisco, CA 94119

Attn: M. A. Lane

Cornell University (2)

Department of Geological Sciences

Ithaca, NY 14853

Conoco Research \& Development

1000 S. Pine

Ponca City, OK 74601

Attn: R. Stolt

B. Sternberg

Dartmouth College

Hanover, NH 03755

Attn: C. Drake

R. E. Stoiber

Earthquake Research Inst. (2)

University of Tokyo

Bunkyo-ku

Tokyo 113, JAPAN

Attn: Shigeo Aramaki

Daisuke Shimozuru

Earthquake Research Inst.

University of Tokyo

Hongo

Tokyo 113, JAPAN

Attn: Kazuaki Nakamura

Exxon Production Research Co.

Box 2189

Houston, TX 77001

Attn: H. R. Gould

National Energy Authority

Laugavegur 116

Reykjavik, ICELAND

Attn: I. B. Fridleifsson

Geological Survey of Japan

Tsukuba-gun, Ibaraga Pref., 305, JAPAN

Attn: Junji Suyama

Ch. Crustal Heat Energy

Attn: S. Kaufman

J. E. Oliver 
Geophysical Laboratory

Carnegie Institution

2801 Upton St, NW

Washington, DC 20008

Attn: H. Yoder

E. F. Osborn

Geothermal Exploration, Inc.

8145 Ronson Road

San Diego, CA

Attn: R. McEuen

Geothermal Resources Intl., Inc. 545 Middlefield Road, Suite 200

Menlo Park, CA 94025

Attn: B. Greider

Lawrence Berkeley Laboratory

University of California

Berkeley, CA 94720

Attn: J. A. Apps

I. S. Carmichael

P. A. Witherspoon

Lawrence Livermore Laboratory

University of California

Livermore, CA 94550

Attn: A. Duba

Livesay Consultants, Inc.

129 Liverpool Drive

Cardiff, CA 92007

Attn: B. Livesay

Los Alamos National Lab (7)

PO Box 1663

Los Alamos, NM 87545

Attn: C. E. Holley, CNC-2,

MS 738

A. W. Laughlin, G-6, MS 978

R. E. Reicker, MS 978

M. C. Smith, G-DOT,

MS 26

C. Herrick, CMB-8

G. Heiken

T. J. Shankland, MS 977

Massachusetts Institute of Technology

Dept of Earth Science

Cambridge, MA 02139

Attn: Keiiti Aki, 54-526
Continental Scientific Drilling Committee

Geophysics Research Board

National Academy of Sciences - National

Research Council

2102 Constitution Avenue, NW

Washington, DC 20418

Attn: R. S. Andrews

National Science Foundation

1800 G. St, NW

Washington, DC 20550

Attn: I. MacGregor, $\mathrm{Rm}$ K300

N. M. Institute of Technology

Dept of Geoscience

Socorro, NM 87801

Attn: A. Sanford

Oak Ridge National Lab

PO Box X

Oak Ridge, TN 37830

Attn: W. L. Marshall

Earth and Environmental Physics Program

Code 464

Office of Naval Research

Arlington, VA 22217

Attn: J. G. Heacock

Oregon State University

Corvallis, OR 97331

Attn: G. Bodvarsson

Phillips Research Center

312 FPB

Bartlesville, OK 74004

Attn: G. Hoover

San Diego State University

Dept of Geol. Sciences

San Diego, CA 92182

Attn: G. Jiracek

Rohr-Universitat Bochum

Institut fur Mineralogie

D-463 Bochum Postfach 102148

WEST GERMANY

Attn: Hans-Ulrich Schmincke

Shell Development Co.

Bellaire Research Center

3747 Bellaire Blvd.

Houston, TX

Attn: R. Thayer 
Southern Methodist University

217 N. L. Heroy Hall

Dallas, TX 75285

Attn: D. D. Blackwell, Head of Geophysics

Stanford University

Petroleum Eng Dept

Stanford, CA 94306

Attn: W. E. Brigham

State Univ of NY at Albany

E215

1400 Washington Ave.

Albany, NY 12222

Attn: K. Burke

Sunoco Energy Development Co.

PO Box 9

Dallas, TX 75251

Attn: A. Ramo

Systems, Science, \& Software

PO Box 1620

La Jolla, CA 92038

Attn: P. Goupillaud

Dr. R. Taschek

2035 47th St.

Los Alamos, NM 87544

Texas A\&M University

College of Geoscience

College Station, TX 77843

Attn: M. Friedman

G. Eaton

Texas A\&M Research Foundation

College Station, TX 77843

Attn: Director

Texas Engineering Experiment Station

College Station, TX 77843

Attn: A. Porter

Union Oil Geothermal

2099 Range Ave.

Santa Rosa, CA 95406

Attn: R. Dondanville
US Department of Energy

(15)

Washington, DC 20545

Attn: A. W. Trivelpiece, ER-1

J. Kane, ER-2

R. H. Kropschot, ER-10

J. S. Coleman, ER-15

G. A. Kolstad, ER-15 (10)

C. Klingsberg, NE 330

US Department of Energy (5) Geothermal/Hydropower Tech. Div. 1000 Independence Ave, SW

Washington, DC 20585

Attn: J. Mock

J. Bresee

D. Allen

D. Clements

R. Toms

US Department of Energy

200 Stovall Street

Alexandria, VA 22332

Attn: T. A. Ladd, Geothermal Program Mgr

US Department of Energy

Albuquerque Operations Office

PO Box 5400

Albuquerque, NM 87185

Attn: Capt. W. J. Barattino,

P.E., USAF

Chief, at Energy

Liaison Office

US Department of Energy (2)

San Francisco Operations Office 1333 Broadway

Oakland, CA 94612

Attn: W. C. Gough

J. Katz

US Department of Energy

333 Market St.

San Francisco, CA 94105

Attn: J. E. Crawford

US Department of State

Office of Nucl and Energy Tech Affairs

Washington, DC 20520

Attn: J. L. Bloom 
US Geological Survey (3)

Cascades Volcano Observatory

5400 MacArthur Blvd.

Vancouver, WA 98661

Attn: D. Peterson

R. Holcomb

T. Casadevall

US Geological Survey

Box 25046

Denver Federal Center

Denver, CO 80225

Attn: F. Frischknecht, MS 964

B. Smith

P. Hoover

US Geological Survey (3)

Hawaiian Volcano Observatory

Hawaii Volcanoes National Park

HAWAII 96718

Attn: R. W. Decker

R. Okamura

Library

US Geological Survey

345 Middlefield Road

Menlo Park, CA 94025

Attn: R. Christiansen

W. A. Duffield, MS 18

H. M. Iyer, MS 77

J. G. Moore

H. Shaw, MS 18

P. Ward

A. H. Lachenbruch

L.J.P. Muffler

US Geological Survey

956 National Center

Reston, VA 22092

Attn: R. T. Helz, MS 959

D. Peck, Director

R. Tilling, MS 906

C. Zablocki, MS 906

R. L. Smith

M. Ryan, MS 959

U S Geological Survey

2255 North Gemini Drive

Flagstaff, AZ 86001

Attn: E. M. Shoemaker
US House Committee on Science and Technology Rayburn Office Bldg B374

Washington, DC 20515

Attn: M. Krebs, ED\&A

US National Park Service

Hawaii Volcanoes National Park

HAWAII 96718

Attn: Superintendent

United Nations Inst for Trn \& Res (UNITAR)

801 United Nations Plaza

New York, NY 10017

Attn: J. Barnea, Special Fellow

University of Alaska

Geophysical Institute

Fairbanks, AK 99701

Attn: J. Kienle

University of California

Department of Geology

Santa Barbara, CA 93106

Attn: C. A. Hopson

University of Hawaii at Manoa

College of Engineering

Honolulu, HI 96822

Attn: Dean P. Yuen

University of Hawaii (2)

Hawaii Inst of Geophysics

Honolulu, HI 96822

Attn: C. Helsley, Head

A. S. Furumoto

University of Minnesota

Inst of Technology

107 Lind Hall

207 Church St, SE

Minneapolis, MN 55455

Attn: Dean R. Staehle

University of Oregon

Center for Volcanology

Eugene, OR 97403

Attn: A. McBirney

H. Waff 
University of Texas

Engineering - Sci Bldg 623

Austin, TX 78712

Attn: F. X. Bostick

University of Texas

Center for Energy Studies

Austin, TX 78712

Attn: M. Dorfman

University of Wisconsin

Dept Geology \& Geophysics

1215 W. Dayton

Madison, WI 53706

Attn: H. F. Wang

Yale University

Dept of Geology \& Geophysics

New Haven, CT 06520

Attn: B. J. Skinner

0301 G. E. Brandvold

1000 J. K. Galt
1500 W. Herrmann

1510 D. B. Hayes

1512 D. F. McVey

1513 D. W. Larson

1513 M. E. Fewell

1540 W. C. Luth

1541 H. C. Hardee (10)

1541 J. L. Colp (30)

1541 J. C. Dunn

1541 R. P. Striker

1542 B. M. Butcher

1543 T. M. Gerlach

1822 E. J. Graeber

1830 M. J. Davis

1834 R. P. Wemple

1840 N. J. Magnani

9740 R. K. Traeger

9741 J. R. Kelsey (20)

8214 M. A. Pound

3141 L. J. Erickson (5)

3151 W. L. Garner (3)

For DOE/TIC

(Unlimited Release) 